\title{
Multimodality Approach in Detection and Characterization of Hepatic Metastases
}

\author{
Pooja G. Patil ${ }^{1}$ Pramesh Reddy ${ }^{1}$ Sudarshan Rawat ${ }^{1}$ \\ 1Department of Radiology, Manipal Hospital, Bangalore, Karnataka, India \\ ${ }^{2}$ Department of Radiology, South Warwickshire NHS Foundation \\ Trust, Warwick, United Kingdom
}

\author{
Rupa Ananthasivan ${ }^{1}$ Rakesh Sinha²
}

Address for correspondence Pooja G. Patil, DNB, Department of Radiology, Manipal Hospital, Bangalore 560017, Karnataka, India (e-mail: drpooja.rad@gmail.com).

\begin{abstract}
Keywords

- hepatic metastases

- MRI

$-C T$

Early detection of liver metastases is important in patients with known primary malignancies. This plays an important role in treatment planning and impacts on further management of certain primary malignancies.

Magnetic resonance imaging (MRI), computed tomography (CT), and positron emission tomography-computed tomography scans are reported to have high accuracy in the diagnosis of intrahepatic lesions. MRI in particular has the advantages of its high tissue sensitivity and its multiparametric approach.

Hepatic metastatic lesions have considerable overlap in their radiological appearance, and in this article the imaging appearance of various hepatic metastasis and approach is described.
\end{abstract}

\section{Introduction}

Liver metastases are the commonest liver tumors and one of the most common indications for liver imaging. Approximately 25 to $50 \%$ of the patients who die with a malignancy have liver involvement. ${ }^{1}$ However, the incidence of benign liver lesions, even in patients with a known malignancy, exceeds that of metastases and it has been reported that 51 to $58 \%$ of the small liver lesions $(<1-1.5 \mathrm{~cm})$ in patients with an underlying malignancy are benign. ${ }^{2,3}$

Imaging of the liver in patients with a known malignancy requires a modality that not only provides high sensitivity, but also provides reliable characterization of lesions, thus allowing differentiation of malignant from benign tumors.

With recent improvements in liver resection technique and options of local ablation of metastases, accurate assessment of the number, size, and segmental location of metastases is required to identify patients that are suitable for surgical or interventional therapy. This is also useful for treatment planning and follow-up imaging post chemotherapy. The resection of solitary metastasis has shown better survival in certain malignancies like colorectal carcinoma, carcinoma thyroid, renal cell carcinoma, and some endocrine tumor. ${ }^{4}$
The volumetric data acquired from imaging are important in determining liver reserve for extended resections. ${ }^{5}$

The choice of imaging varies significantly across institutions depending on local radiologist expertise and preference, availability of type of equipment. Patient-related factors such as renal failure, cardiac pacemakers, and contrast allergy may also impact the choice of imaging modalities.

Advances in imaging techniques, notably computed tomography (CT), magnetic resonance imaging (MRI), ultrasound (US), positron emission tomography (PET), and integrated positron emission tomography-computed tomography (PET-CT) imaging, have increased the ability to detect and characterize focal liver lesions.

To summarize, imaging has the following important roles in the assessment of liver metastases:

- Screening for metastatic disease.

- Characterization and differentiation of metastasis from benign lesions.

- Presurgical segmental localization for evaluation of resectability.

- Volumetric evaluation of liver lobes and segments prior to surgical resection.

- Monitoring treatment and surveillance following treatment. 


\section{Ultrasound}

US is the most widely available modality for liver imaging. The major advantages of US are its temporal resolution and availability. It offers a rapid noninvasive method for screening patients with suspected liver metastases.

The ability to visualize a lesion in the liver is dependent on liver to lesion contrast and spatial resolution. Smaller lesions that are hypoechoic or hyperechoic are well visualized, while smaller isoechoic lesions may be overlooked. US is dependent on the operator and on the body habitus of the patient. The subdiaphragmatic area can often be a blind spot on US. Ultrasound is therefore no longer viewed as the primary imaging modality to diagnose metastases. ${ }^{6}$

The US appearance of metastases varies with different primaries and changes with subsequent chemotherapy. Hypoechoic appearance is more common (approximately $65 \%$ ) than isoechoic or hyperechoic metastases. ${ }^{7}$ Metastases from breast, lung, pancreas, stomach, and colon cancers are predominantly hypoechoic (-Fig. 1A). Cystic liver metastases may be seen in metastases from ovarian and pancreatic cancers ( - Fig. 1B). Occasionally, metastases may have a target pattern. This refers to iso/hyper/or occasionally hypoechoic center with a hypoechoic rim or periphery. This appearance is quite specific for hepatic metastases ( - Fig. 1C, D). ${ }^{7}$

Hyperechoic metastases are less prevalent and are usually secondary to thyroid and renal primaries ( - Fig. 1E). Metastases may have calcification, particularly from treated mucinous adenocarcinomas and rarely from osteosarcomas ( - Fig. 2).
An important differential for hyperechoic lesions in the liver is hemangiomas. A differentiating factor is the presence of posterior acoustic enhancement in hemangiomas. However, hemangiomas with atypical features may be difficult to distinguish from metastases

Mass effect is important for the detection of isoechoic lesions. It manifests as deviation or invasion of the intrahepatic vasculature and/or bulges in the liver contour.?

US has moderate sensitivity for detection of hepatic metastases. A meta-analysis demonstrated the sensitivity

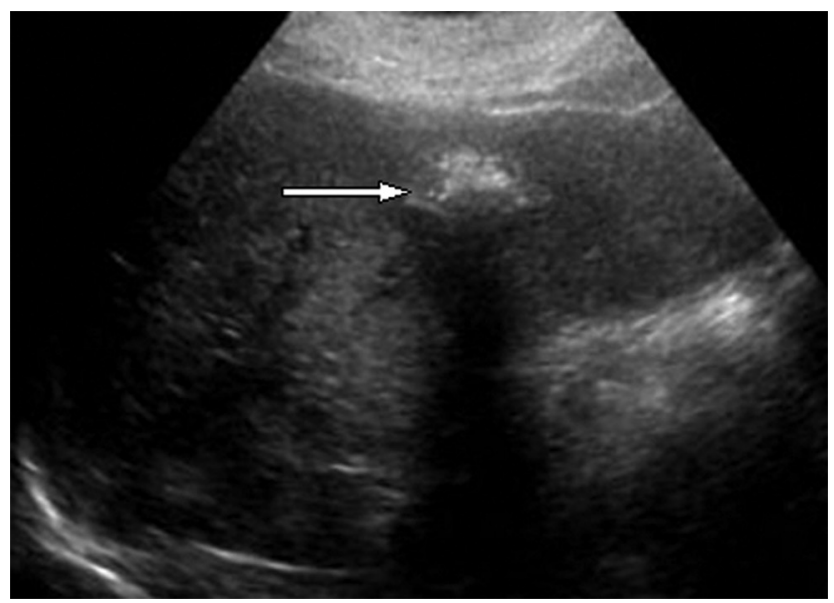

Fig. 2 Ultrasound showing a focal calcified metastatic deposit in the liver (white arrow) seen in mucinous adenocarcinoma of stomach, colon, and ovaries.
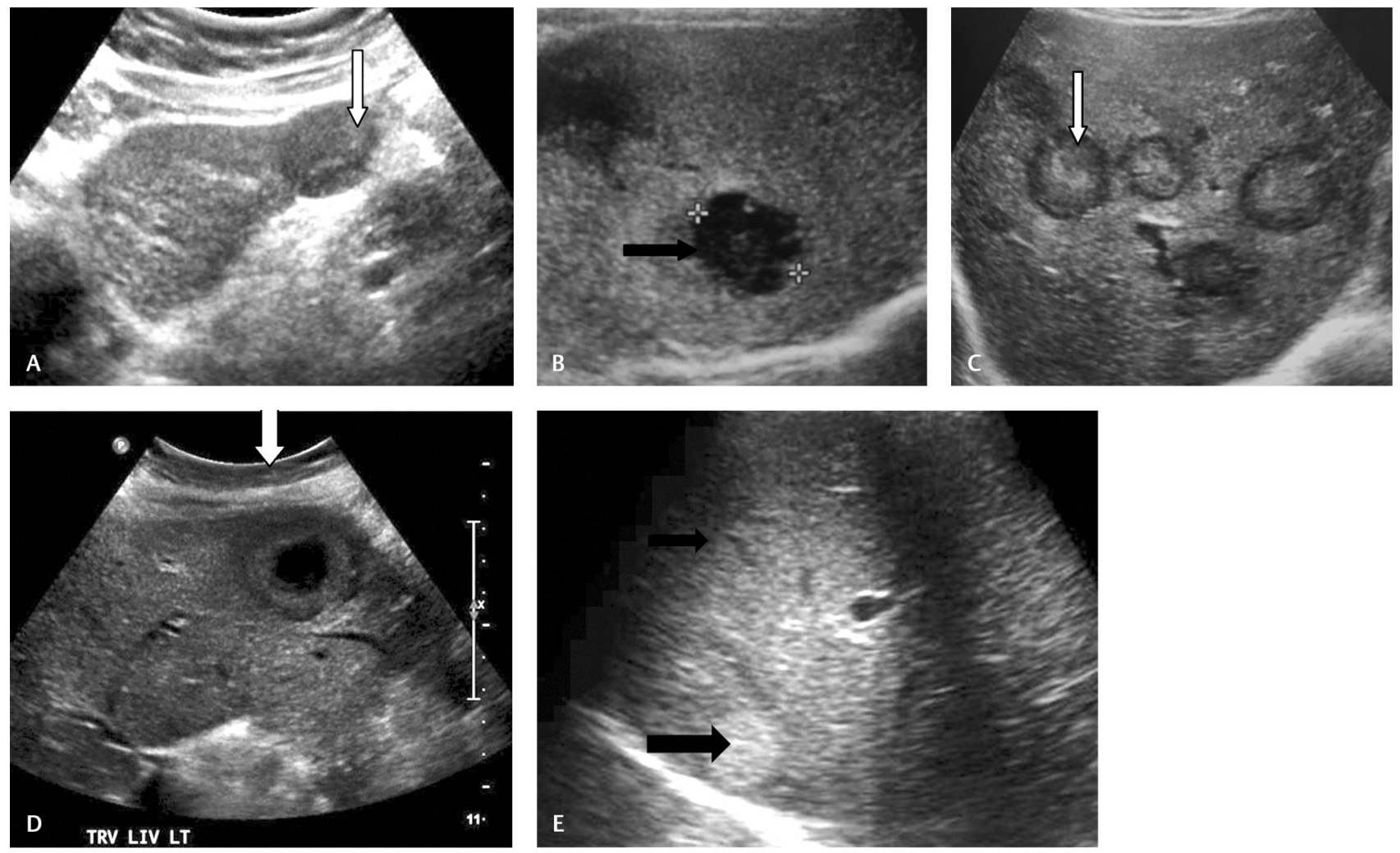

Fig. 1 Ultrasound appearances of liver metastases. (A) Hypoechoic lesion (white bold arrow)-most commonly seen in lung cancer, breast cancer, pancreatic adenocarcinoma. (B) Cystic metastases (black bold arrow) seen in ovarian cancer, squamous cell carcinoma. (C,D) Hyperechoic lesion (white bold arrow) with peripheral halo-target sign-highly specific for metastases-lung cancer. (E) Hyperechoic metastases (black arrow) seen in endocrine tumors of pancreas, renal cell carcinoma, thyroid carcinoma, colorectal carcinoma. 
and specificity of US in detection of colorectal metastases to be 63.0 and $97.6 \%$, respectively. ${ }^{8}$

\section{Doppler Imaging}

Hypoechoic metastases usually demonstrate minimal peripheral vascularity and hyperechoic lesions on the other hand show increased vascularity within the lesion. Doppler studies may be useful in diagnosing focal fatty changes, focal nodular hyperplasia (FNH), and benign biliary cysts. In FNH, a spoked-wheel pattern may be seen within the lesion. In focal fatty changes normal vessels are seen running through the area of altered echotexture and in cases of cysts no color uptake seen within.

\section{Contrast-Enhanced Ultrasound}

Multiple studies have demonstrated a high accuracy for contrast-enhanced ultrasound (CEUS) in characterizing and detecting liver lesions, in the range of 87 to $91 \%,{ }^{9-16}$ which is nearly equivalent to MRI.

However, reports in the literature are variable. Vialle et al $^{16}$ recently published data to indicate CEUS to be significantly inferior to CT in the preoperative detection of liver metastases (sensitivity CEUS 64.5 vs. CT $80.4 \%$ ) referenced to intraoperative ultrasound examinations (IOUS). ${ }^{17}$ Reasons for above could be due to skill set of observer, poorly standardized landmarks for CEUS, and poor reproducibility.

Drawbacks of CEUS are similar to conventional US including operator dependency, limitation in obese or uncooperative patients and meteorism or intestinal interposition. Further limitations arise from the limited spatial resolution resulting in the smallest detectable metastases in the range of 3 and $5 \mathrm{~mm} .^{18}$

In the evaluation of liver lesions, arterial-phase imaging on CEUS provides incremental value in lesion characterization, whereas the portal venous phase (PVP) and delayed phase improve lesion detection as almost all metastases show washout, unlike with CT and MRI, where shift of contrast into the interstitial space may conceal washout. ${ }^{19}$
Appearances on arterial phase depend on the extent of arterial supply/perfusion. Hypervascular metastases seen in thyroid, renal, and occasionally breast carcinomas show homogenously enhancing lesions with some lesions showing necrotic areas centrally during the arterial phase (-Figs. 3A and 4). Hypoechoic metastases which are commonly seen in gastrointestinal primaries have poor arterial perfusion and hence show peripheral enhancement ${ }^{7}$ (-Fig. 3B).

At the start of the portal phase, peripheral enhancement washes out with the lesion appearing increasingly hypoechoic. During the delayed phase, metastases are often very well defined, often with sharp, "punched out" borders. ${ }^{7}$

Both portal-venous and delayed phase imagings markedly increase the contrast between the enhancing normal liver and the nonenhancing metastases and thus improve detection.

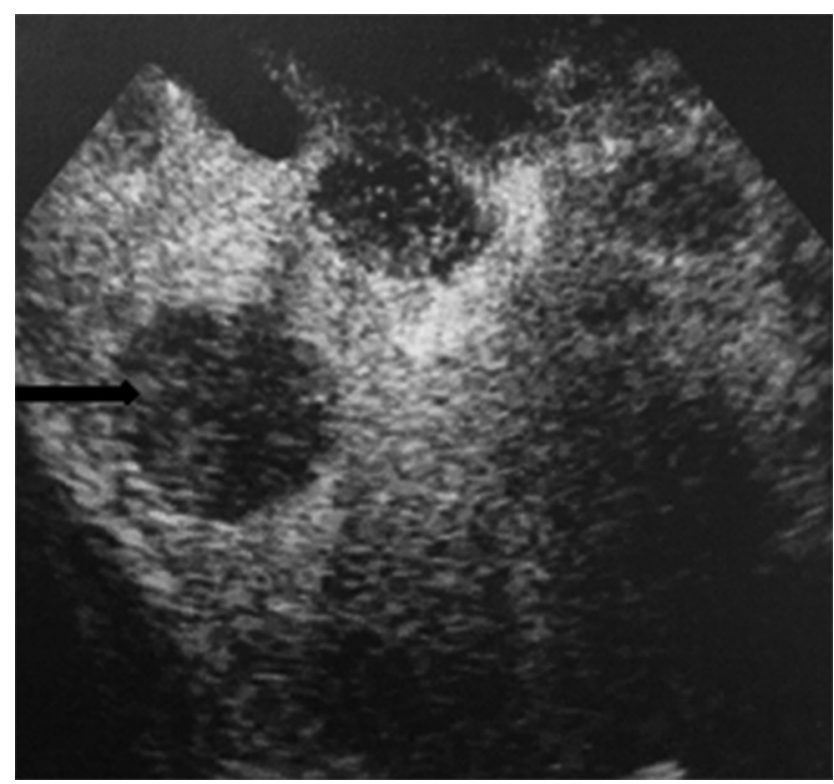

Fig. 4 Contrast-enhanced ultrasound of liver showing nonenhancing hypoechoic lesions (black arrow) in liver-hypovascular metastases.
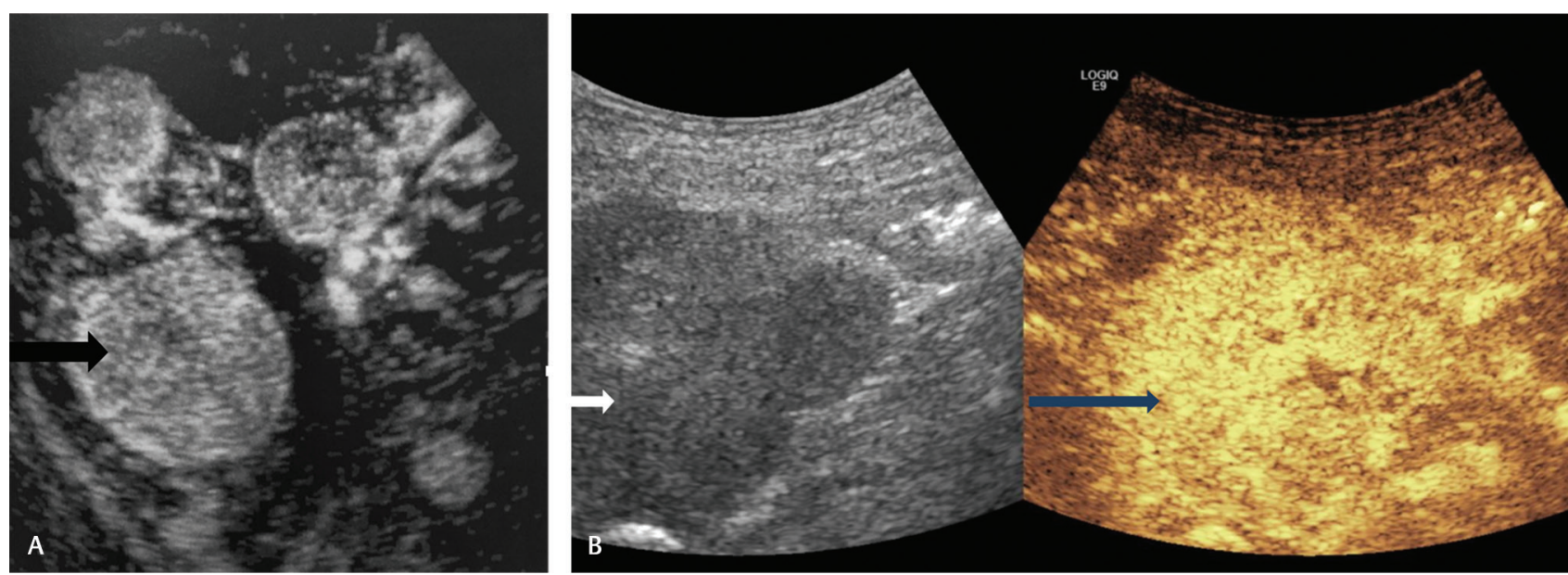

Fig. 3 Contrast-enhanced ultrasound of liver showing (A) multiple enhancing lesion in liver suggestive of hypervascular metastases and (B) hypoechoic lesions (white arrow) in liver and shows enhancement (blue arrow) on postcontrast study. 
The major advantage of CEUS is the ability to use it in patients who may have MRI contraindications (such as pacemakers) or in patients who cannot undergo contrast CT/MRI examinations due to renal impairment.

\section{Intraoperative Ultrasonography}

IOUS is an accurate and sensitive imaging technique for detecting liver metastases at the time of primary tumor resection or resection of previously identified hepatic metastases. ${ }^{20-24}$

Dedicated high frequency transducers (5-10 MHZ), such as $I$-shaped or flat $T$-shaped linear probes allow nearly the entire liver to be scanned, including blind spots like the hepatic dome and the right lateral portion without image quality degradation due to overlying structures such as subcutaneous fat, bowel gas, or the ribs. ${ }^{6}$ Furthermore, IOUS provides real-time imaging capabilities, and thus, under IOUS guidance, it is possible to perform intraoperative diagnostic and therapeutic procedures for focal hepatic lesions like intraoperative ethanol injection, radiofrequency ablation (RFA), and microwave ablation (MWA).4,9,25,26 IOUS has the advantage of an excellent spatial resolution with a good sonic window, capability of performing procedures from various planes and angles that may shift over the course of an operation, and accessibility, especially in procedures involving deeply located lesions or lesions hidden by overlying structures. $5,27,28$

There is no doubt that IOUS increases both the sensitivity and accuracy of the detection of focal hepatic lesions compared with conventional gray-scale ultrasonography. ${ }^{17,18}$ In fact, some studies have shown that IOUS is comparable to MRI.

Conlon et $\mathrm{al}^{26}$ reported that in patients with hepatic metastases from colorectal cancer, IOUS identified additional hepatic lesions in $47 \%$ of the patients compared with preoperative MRI. Several other authors have reported similar findings $s^{3,9,12,13}$ and have suggested that IOUS should be routinely employed during hepatic resection for colorectal metastases.

Wagnetz et al, however, ${ }^{27}$ reported that the sensitivities of multidetector computed tomography and MRI were equivalent or higher to that of IOUS in the identification of hepatic segments involved in hepatic malignancies, as well as having a higher predictive value for identifying tumor-free hepatic segments. This has been supported by other authors too ${ }^{29-}$ 31 and hence it can be argued that though IOUS is a sensitive and accurate imaging technique for detection of focal lesions, particularly in colorectal metastases, multidetector CT (MDCT) and MRI yield similar results.

\section{Computed Tomography}

$\mathrm{CT}$ is the preferred examination for initial assessment and subsequent surveillance for metastatic disease after diagnosis of a primary neoplasm due to its ability to image the liver and potential sites of extrahepatic disease (i.e., nodes, peritoneum, chest) during the same examination. ${ }^{32}$
Current MDCT scanners provide increased speed of acquisition with high resolution during a single breath hold, thus eliminating artifacts. Usually the initial scan in a patient with a known malignancy who is being evaluated for the presence of liver metastases is a multiphase scan. Multiphase CT is known as a reliable method in the detection of liver metastases, reaches sensitivity of approximately $92 \%,{ }^{32}$ Kuszyk et al ${ }^{32}$ showed an overall sensitivity of $91 \%$ for portal venous phase scanning in detecting malignant liver tumors greater than $1 \mathrm{~cm}$, but only a sensitivity of $56 \%$ for lesions smaller than $1 \mathrm{~cm}$.

Several studies have reported improved detection and characterization using multiphase scanning. Bonaldi et $\mathrm{al}^{33}$ reported the detection of an additional $8 \%$ of lesions using dual-phase scanning. Hollett et $\mathrm{a}^{34}$ showed an increase in detection and conspicuity of malignant lesions smaller than $1.5 \mathrm{~cm}$ using this technique.

Most metastatic deposits are best visualized on a portal venous phase unless hypervascular metastases such as those from renal, thyroid, breast, carcinoid, islet cell, and melanoma malignancies are being imaged which are well seen in the arterial phase. ${ }^{31}$ The addition of arterial phase scans routinely does not result in greater yield or conspicuity of metastases and may not be required in all cases. ${ }^{36,37}$

Honda et al concluded that adding a late arterial phase to a two-phase imaging consisting of unenhanced and PVP improved the detectability, especially for lesions $<10 \mathrm{~mm}$ in size $^{38}$ and Silverman reported an increased lesion detection rate of 8 to $13 \%$ by adding late arterial phase to portal venous phase. ${ }^{39}$

Follow-up particularly in cases where the metastases are best visualized in the portal venous phase can be done in one phase to reduce radiation burden.

Liver metastases become less conspicuous or even completely obscured in the equilibrium phase (beginning approximately 100 seconds after injection initiation). ${ }^{31}$ Hence equilibrium phase is not routinely recommended for detection of liver metastases.

CT has a lower sensitivity for nodules of $\leq 10 \mathrm{~mm}$ and particularly for nodules of $\leq 5 \mathrm{~mm}$, while the sensitivity reaches $100 \%$ for larger $(>20 \mathrm{~mm})$ nodules. Further studies are required to establish the role of alternative imaging modalities, for example, gadoxetic acid-enhanced MRI in improving sensitivity in the detection of subcenter meter hepatic metastases particularly in patients with suspected colorectal liver metastases. ${ }^{40}$

\section{Imaging Appearances of Liver Metastases on CT}

On precontrast images, metastases are usually seen as hypoattenuating or hypodense lesions. They may be seen as hyperattenuating lesions if they contain hemorrhage or high protein such as mucin as in hemorrhagic metastases or metastases from mucinous tumors (- Fig. 5A, D).

Calcifications may also be seen in metastases from mucinous tumors of the ovaries, medullary thyroid cancer, or mucinous tumors of the gastrointestinal tract and in post TACE status (- Fig. 5B, C). ${ }^{41}$ 

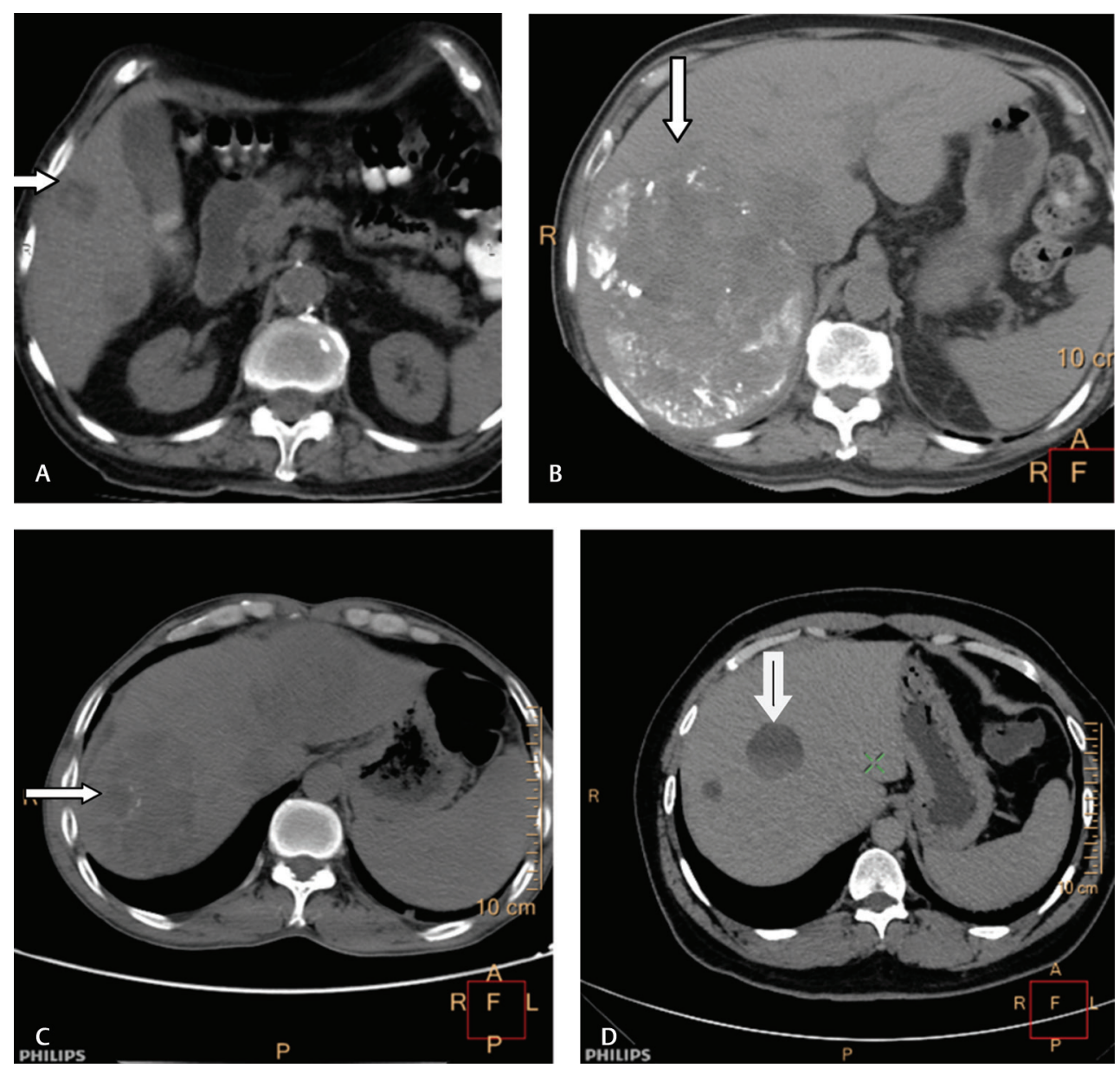

Fig. 5 Plain computed tomography showing (A) hypodense lesions with areas of hyperdensity (white arrow) suggestive of fluid layering. (B) Large hypodense lesion in the right lobe of liver with areas of calcification-postchemoembolization. (C) Hypodense lesion with calcified foci within, seen in mucinous metastatic deposit. (D) Hypodense lesion with hyperdense content (white arrow) suggestive of hemorrhagic lesion.

On postcontrast imaging liver metastases may be (-Table 1; - Figs. 6-13):

- Avascular.

- Hypovascular.

- Isovascular.

- Hypervascular.

\section{Other Findings}

An uncommon secondary finding, capsular retraction adjacent to a mass, has been reported to be highly specific for malignancy. ${ }^{42,43}$

Apicella et al $^{43}$ reported five cases in which hepatic vessels coursed undisturbed through low-attenuation areas proven to be metastases. This was previously thought to be related to steatosis and is an important pitfall which has to be kept in mind.

\section{MRI}

MRI plays an increasingly important role in identifying hepatic metastases because of the excellent contrast and tissue resolution. MRI helps to detect and also helps to characterize liver lesions and differentiate benign from malignant masses. It offers high intrinsic soft-tissue contrast, technical versatility for pulse sequence selection, molecular and anatomical information, sensitivity to blood flow and contrast enhancement, and multiplanar capability. ${ }^{35}$ Apart from normal extracellular agents like gadopentetate dimeglumine, liver-specific contrast agents like gadoxetic acid (Primovist or Eovist) or gadobenate dimeglumine (Multihance) helps in better characterization of lesions. These contrast agents are taken up to varying degrees by functional hepatocytes and excreted by bile. They cause T1 shortening of liver parenchyma and bile ducts, thereby increasing the contrast to noise ratio for nonhepatocellular lesions. ${ }^{45}$

Super paramagnetic iron oxide particles are captured by the system in the liver and spleen. They cause signal loss of liver and help in increasing the conspicuity of liver lesion, although their use has been superceded by liver-specific contrast agents.

Protocols include T2-, T1-, T1-weighted chemical shift imaging, diffusion imaging, and contrast-enhanced multiphasic imaging with liver-specific contrast agents including a delayed scan (hepatobiliary phase).

Timing of hepatobiliary phase using hepatobiliary contrast depends on the type of contrast agent used. Recently hepatobiliary contrast agents have come to the forefront in 
Table 1 Imaging patterns of metastases on CT and MRI

\begin{tabular}{|c|c|c|}
\hline Patterns/Type of primaries & CT & MRI \\
\hline $\begin{array}{l}\text { Avascular lesion: } \\
\text { Ovarian metastases } \\
\text { Postchemotherapy or chemoembolization } \\
\text { Following ablation (radiofrequency, microwave, and } \\
\text { cryoablation). }\end{array}$ & $\begin{array}{l}\text { Lack of enhancement in arterial and venous } \\
\text { phases. } \\
\text { Or } \\
\text { Occasional marginal peripheral enhance- } \\
\text { ment in venous phase. } \\
\text { Or } \\
\text { Cystic or necrotic appearance. }^{34}\end{array}$ & $\begin{array}{l}\text { Lack of enhancement in arterial } \\
\text { and venous phases. }\end{array}$ \\
\hline $\begin{array}{l}\text { Isovascular } \\
\text { Colonic, thyroid, and breast metastases } \\
\text { Postchemotherapy or chemoembolization. }\end{array}$ & $\begin{array}{l}\text { Similar enhancement to liver parenchyma } \\
\text { (- Fig. 6). }\end{array}$ & $\begin{array}{l}\text { Similar enhancement to liver } \\
\text { parenchyma. }{ }^{34} \text { (-Fig. 11). }\end{array}$ \\
\hline $\begin{array}{l}\text { Hypovascular } \\
\text { Colonic, pancreatic, small bowel, lung, bladder, and } \\
\text { prostatic metastases. }\end{array}$ & $\begin{array}{l}\text { Lesser enhancement than liver parenchy- } \\
\text { ma. } \\
\text { Or } \\
\text { Thin rim like peripheral enhancement in } \\
\text { arterial and later phases ( } \mathbf{- F i g . ~} 7 \text { ). } \\
\text { Or } \\
\text { Progressive mild enhancement in the portal } \\
\text { phase but hypodense to background liver } \\
\text { parenchyma. }{ }^{35}\end{array}$ & $\begin{array}{l}\text { Lesser enhancement than liver } \\
\text { parenchyma. } \\
\text { Or } \\
\text { Thin rim like peripheral enhance- } \\
\text { ment in arterial and later phases. } \\
\text { Or } \\
\text { Progressive mild enhancement in } \\
\text { the portal phase but hypointense } \\
\text { to background liver parenchyma }{ }^{35} \\
\text { (- Fig. 12). }\end{array}$ \\
\hline $\begin{array}{l}\text { Hypervascular } \\
\text { Breast, renal carcinoid, neuroendocrine, islet cell, } \\
\text { thyroid, sarcoma, and melanoma metastases. }\end{array}$ & $\begin{array}{l}\text { Intense enhancing lesion in arterial phase } \\
\text { followed by centripetal enhancement with } \\
\text { washout in portal phase (- Fig. 8). Small } \\
\text { lesions may appear as hyperenhancing foci } \\
\text { mimicking hemangiomas (- Fig. 9). } \\
\text { Or } \\
\text { If larger then peripheral thick hyper- } \\
\text { enhancement with progressive central } \\
\text { enhancement }{ }^{35} \text { (-Fig. 10). }\end{array}$ & $\begin{array}{l}\text { Intense peripheral thick ring-like } \\
\text { enhancement in arterial phase } \\
\text { followed by progressive centripe- } \\
\text { tal enhancement with peripheral } \\
\text { washout in portal phase. } \\
\text { Or } \\
\text { Intense uniform enhancement on } \\
\text { the arterial phase images and wash } \\
\text { out in portal phase }{ }^{35} \text { (-Fig. } 13 \text { I, II). }\end{array}$ \\
\hline
\end{tabular}

Abbreviations: $\mathrm{CT}$, computed tomography; MRI, magnetic resonance imaging.

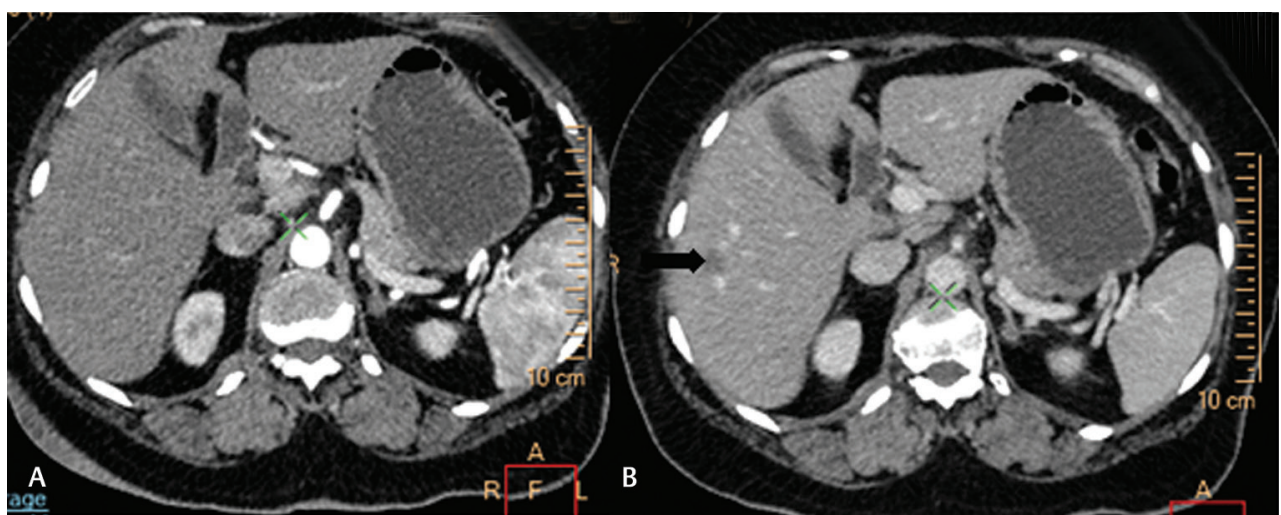

Fig. 6 Computed tomography showing hypodense lesion in liver seen only in portal phase (B, black bold arrow), not visualized in arterial phase (A) images suggestive of isovascular metastatic deposit.

differentiating whether a lesion is of hepatocellular origin or not. At our institute, we use multiHance (dose $0.1 \mathrm{mmol} / \mathrm{kg}$ ) and perform 1 to 2 hours delay scan. Alternatively, if Eovist is used (dose $0.025 \mathrm{mmol} / \mathrm{kg}$ ), imaging of the hepatobiliary phase is done for 20 to 30 minutes. The advantage of hepatobiliary contrast agents is that imaging is not phase dependent and does not have to be precisely timed.

\section{MRI Appearances}

Metastases appear predominantly hypointense on T1-weighted images (-Fig. 14) but occasional high signal intensity on T1 may be seen due to the presence of paramagnetic substances for example extracellular methemoglobin in hemorrhagic metastases, melanin in malignant melanoma (-Fig. 15), protein in ovarian adenocarcinoma, multiple myeloma and pancreatic mucinous cystic tumors, and coagulative necrosis in colonic adenocarcinoma. ${ }^{41}$

On T2-weighted sequences metastases show mild to moderate high signal intensity (-Fig. 16).

Few appearances of liver metastases are described ${ }^{46}$ :

- The halo sign: central area of lower signal intensity relative to the higher intensity tumor periphery, commonly seen in colorectal carcinoma.

- Target sign: a central area of high signal intensity with peripheral low signal corresponds to central liquefactive necrosis (-Fig. 11). 

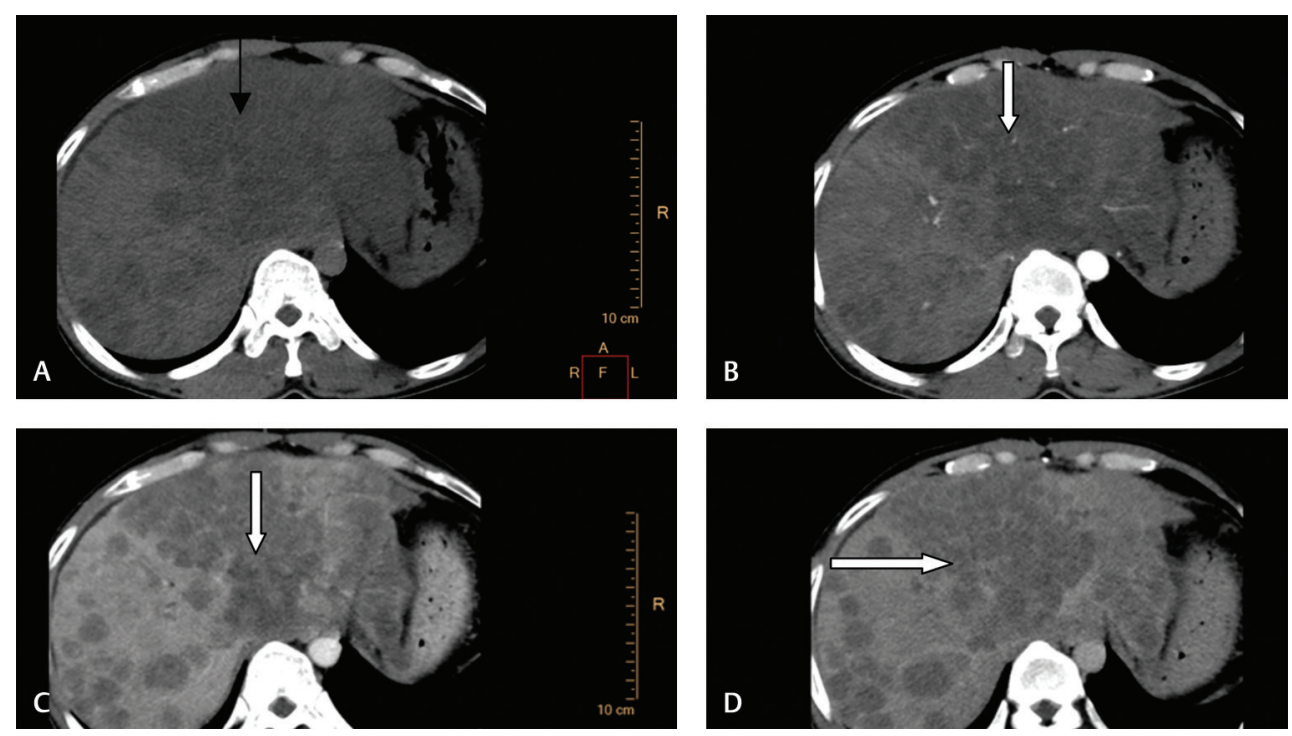

Fig. 7 (A) Plain CT abdomen showing multiple hypodense lesions in liver (small white arrows). (B) Arterial phase-multiple nonenhancing hypodense lesions in liver (white arrowheads). (C) Venous and (D) delayed phase-multiple hypodense lesions in liver with mild peripheral wall enhancement on portal venous phase (black arrows) and delayed phase (black arrowheads). Case of multiple liver metastases from colonic adenocarcinoma, urothelial cell carcinoma, pancreatic ductal adenocarcinoma, small bowel adenocarcinoma, lung carcinoma, bladder carcinoma, and prostate carcinoma
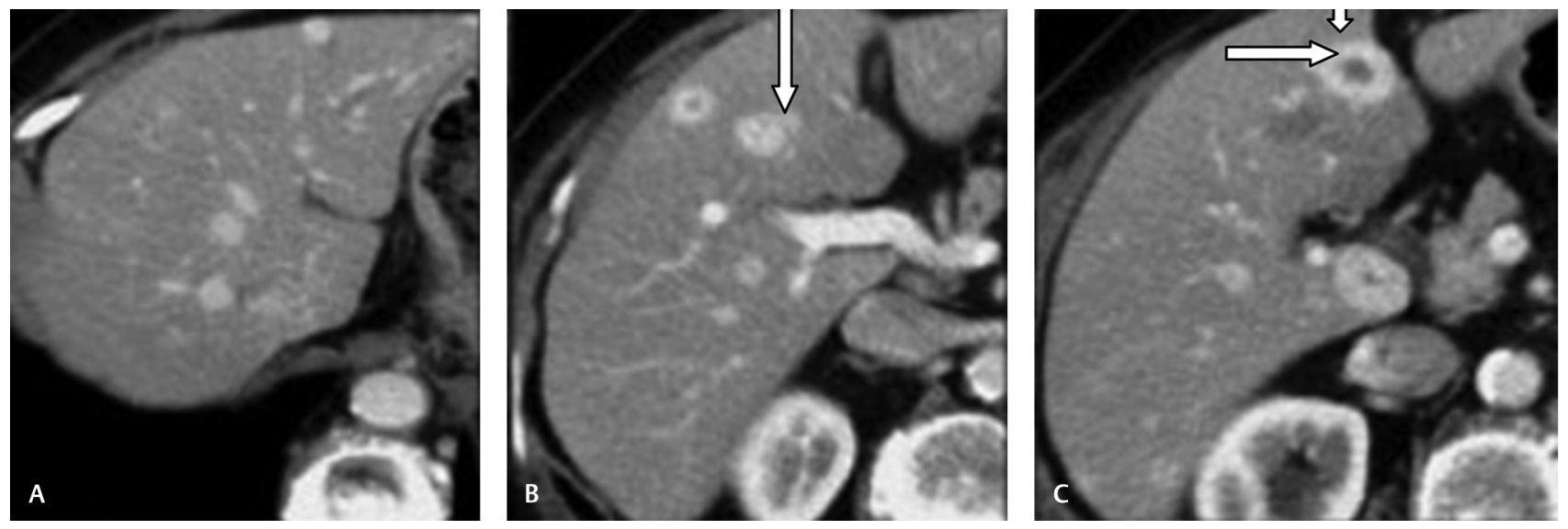

Fig. 8 (A-C) Multiple hypervascular enhancing lesions in liver in arterial phases (black arrows) suggestive of hypervascular metastatic deposits from known case of endocrine tumor of pancreas.

- The doughnut sign is seen on T1-weighted images as a low-signal-intensity rim surrounding and even lower signal intense center.

\section{Enhancement Characteristics}

The vascularity of liver metastases is generally similar to the vascularity of the primary neoplastic lesion. ${ }^{46}$ Classically, metastases from colon, bladder, prostate, and lung carcinoma are hypovascular, and those from thyroid carcinoma, carcinoid tumor, neuroendocrine tumor, and renal cell carcinoma are hypervascular. ${ }^{47}$

Four patterns of hepatic lesion enhancement are described:

1. Peripheral ring enhancement.

2. Heterogeneous enhancement.

3. Homogenous enhancement.

4. Negligible enhancement.
The enhancement patterns depend on the size of the lesion with most common and characteristic pattern being peripheral ring enhancement ( $\boldsymbol{- \text { Fig. }}$ 17A) especially when the lesion is larger than $1.5 \mathrm{~cm}$.

On hepatic arterial dominant phase images, the outer margin of the metastasis representing the most vascularized portion enhances prominently and the inner portion has negligible enhancement but on the interstitial phase the outer margin demonstrates a decrease in the degree of enhancement that may appear as heterogeneous fading to near isointensity or washout, and the inner area shows an increase in the degree of enhancement. ${ }^{41}$

This centripetal enhancement with peripheral wash out is as a specific sign for metastases (specificity 100\%). Although present in both hypervascular and hypovascular lesions, the peripheral washout is more conspicuous and observed more frequently in hypervascular metastases, particularly in neuroendocrine and carcinoid tumors. ${ }^{48}$ 

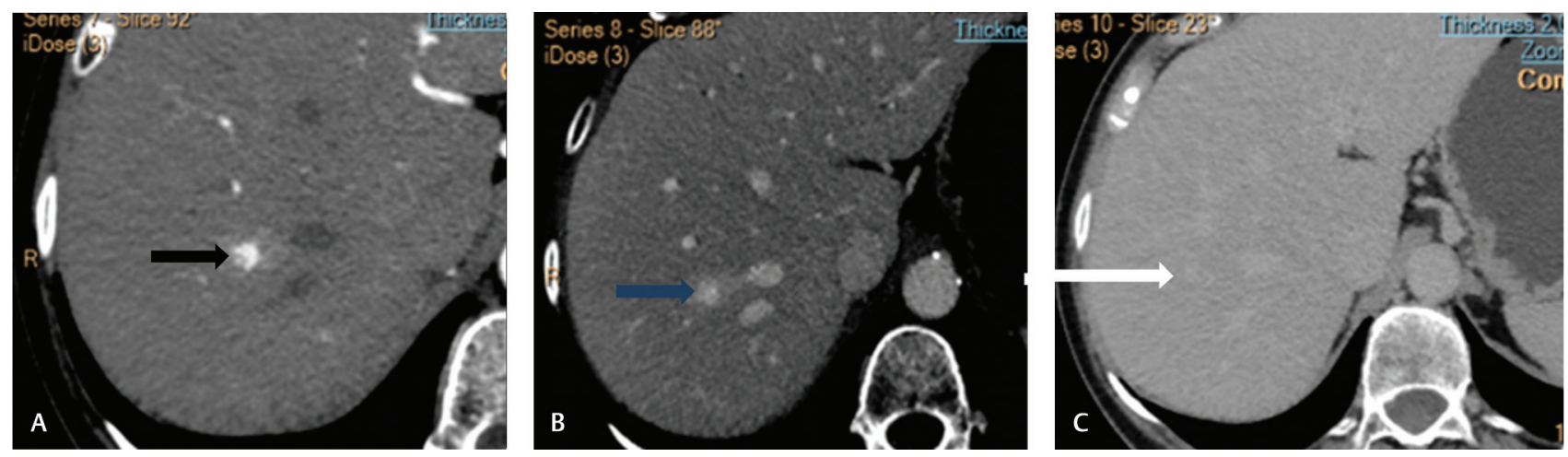

Fig. 9 Contrast study of liver showing (A) well-defined arterially enhancing lesion (black arrow) with (B) progressive enhancement of lesion on venous phase (blue arrow) and iso-dense appearance on delayed phase (C, white arrow)-suggestive of flash hemangioma.
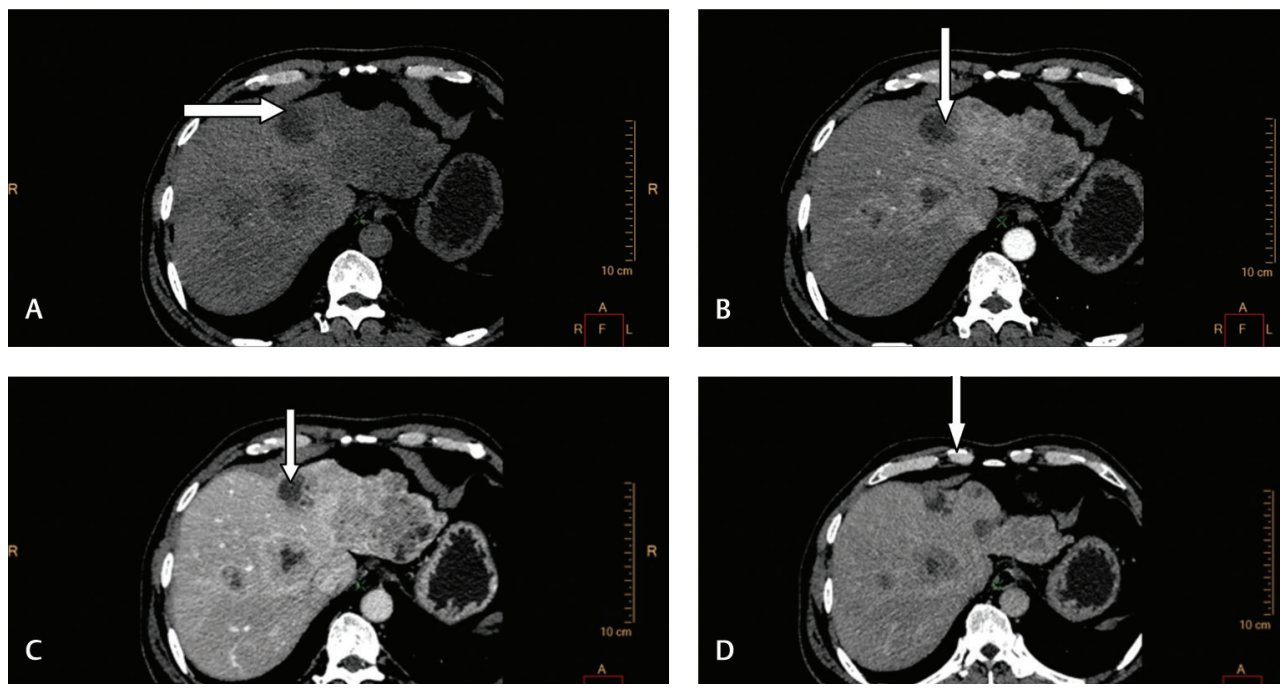

Fig. 10 Multiple hypodense lesions in liver on plain CT (A) with peripheral thick wall enhancement on arterial phase (B) and venous phase (C) with progressive enhancement on the delayed phase (D).

This peripheral ring enhancement may reflect the pattern of growth of metastases with a parasitic blood supply taken from the surrounding liver regardless of the abundance of vascular supply ${ }^{49}$ As the tumor reaches a threshold size, only the peripheral part remains well vascularized, whereas cells in the central portion of the tumor lose the close proximity with the vascular supply and become compressed, necrotic, or replaced by fibrosis. ${ }^{50}$ Peripheral thick enhancement with a central nonenhancing area gives a target like appearance ( - Fig. 17E).

The pattern of homogenous enhancement ( - Fig. 17B) is seen predominantly in lesions less than $1.5 \mathrm{~cm}$. This homogeneous early enhancement makes the differentiation of these metastases from homogeneously enhancing hemangioma smaller than $1.5 \mathrm{~cm}$ problematic, especially in the absence of other larger metastases. ${ }^{51}$

The heterogeneous enhancement ( $\mathbf{- F i g}$. 17C) is less common and is seen in lesions larger than $1.5 \mathrm{~cm}$, it reflects necrosis or hemorrhage within the metastases. This pattern is not specific for metastases, and can be observed in primary malignant liver lesions, especially hepatocellular carcinomas. ${ }^{47}$

Negligible enhancement pattern is seen in avascular metastases ( - Fig. 17D).
There may be perilesional enhancement, which refers to enhancement that occurs beyond the margins of the lesion delineated on precontrast images. It is more common in hypovascular metastases and uncommon in hypervascular metastases, and may develop due to hepatic parenchyma compression, associated peripheral desmoplastic reaction, inflammatory infiltrates, and neovascularization This is observed most frequently in colon cancer and pancreatic ductal adenocarcinoma. ${ }^{41,52}$

In hepatobiliary phase, the contrast gets excreted by liver and taken up by hepatocytes containing lesions. Hepatic malignancies and metastases show no contrast uptake and appear as defects. Other benign lesions like hepatic cysts and hemangioma, which also do not take up hepatobiliary contrast, are well characterized by routine multiparametric magnetic resonance (MR) sequences and contrast characteristic features.

Studies have showed improved detection of metastases with diffusion-weighted images compared with $\mathrm{T} 2$-weighted imaging ( - Fig. 18) and is explained by the improved image contrast with the use of low $b$ values and lack of blurring with single-shot spin echo-planar imaging. ${ }^{53}$ 

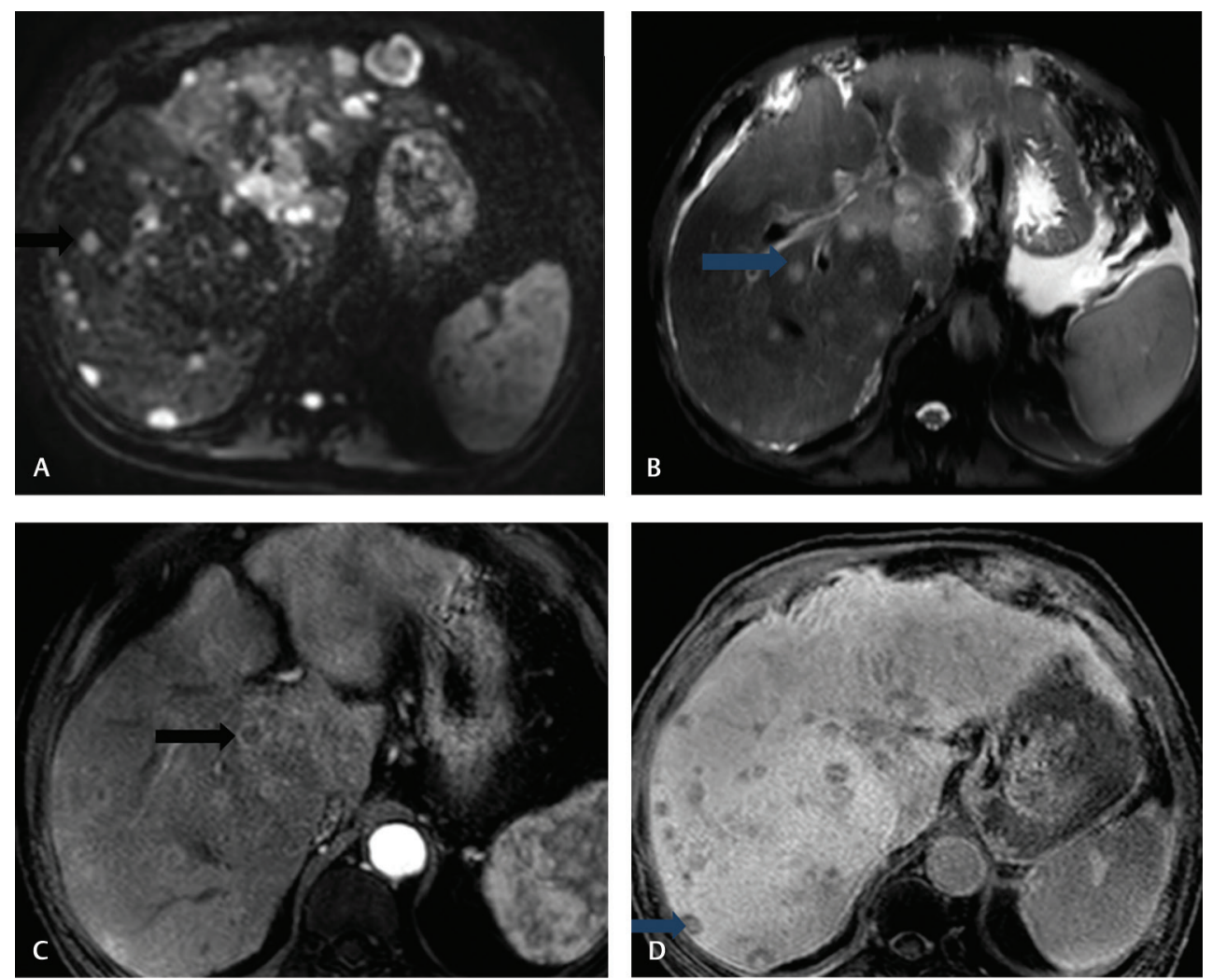

Fig. 11 (A) DWI (black arrow) showing multiple focal areas of restricted diffusion. (B) T2-weighted image (arrow) shows corresponding hyperintensities. (C) Arterial phase imaging shows ring enhancement (arrow). (D) Delayed phase shows target appearance of some of the lesions (arrow).
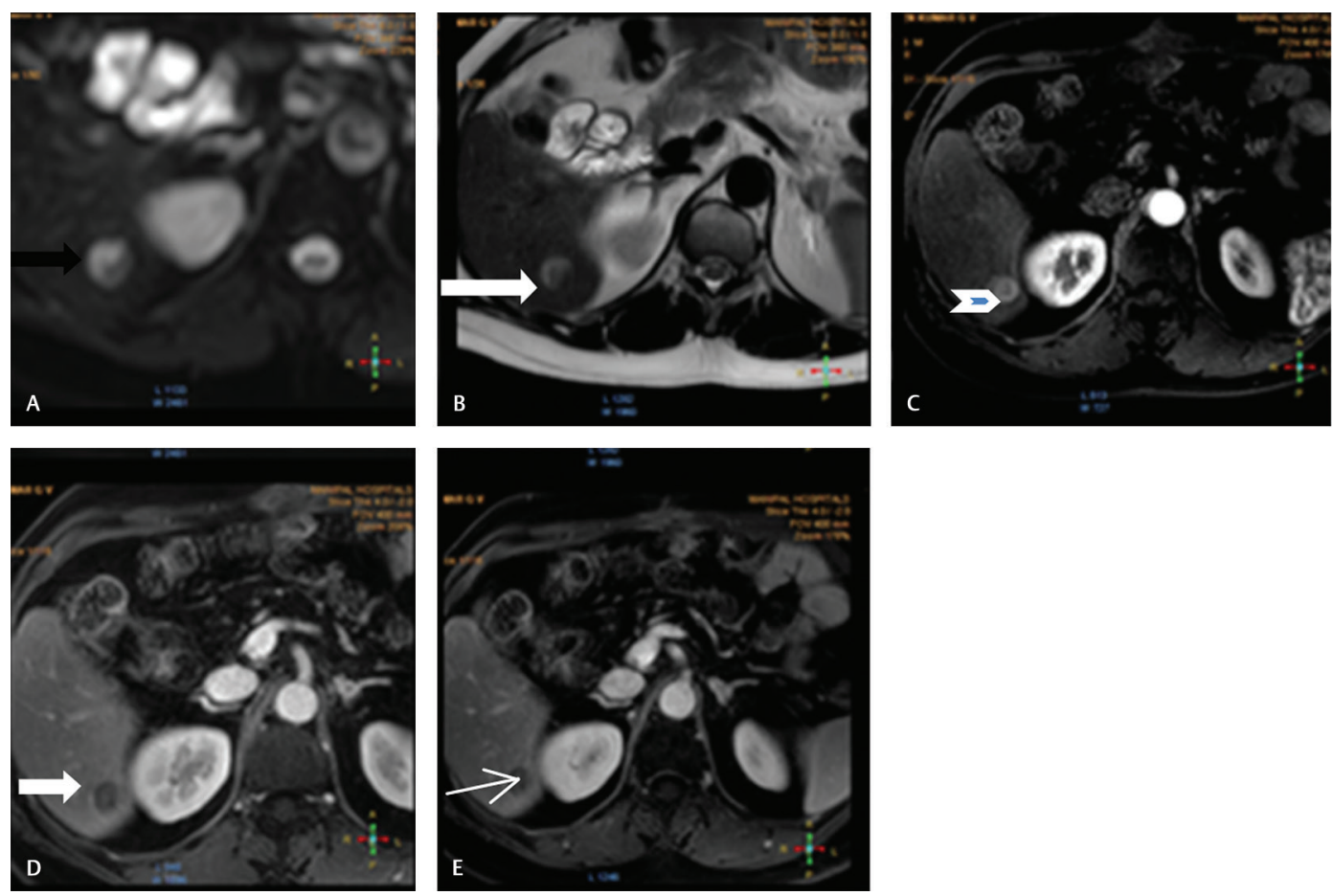

Fig. 12 Multiparametric MRI appearance of liver metastases. (A) Axial DWI images showing focal area of restricted diffusion (arrow) with high signal on T2 weighted image (white arrow). (C) Post contrast there is ring enhancement on arterial phase (arrowhead). (D) There is washout of contrast on venous phase (arrow). (E) Delayed phase shows washout and hypointense lesion. 

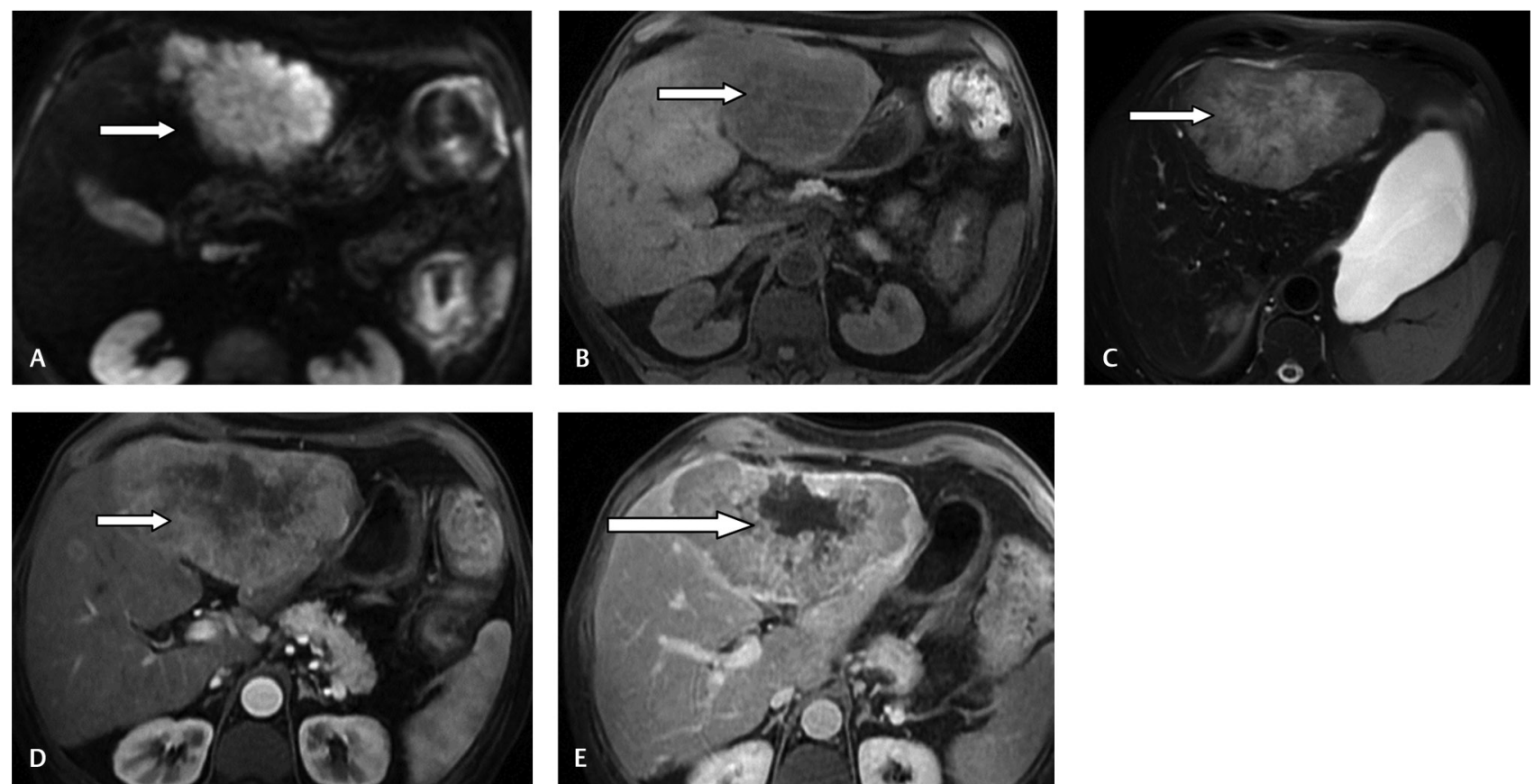

Fig. 13 MRI of the liver: (A) Axial DWI image shows restricted diffusion (arrow). (B) Hypointensity on T1-weighted image (white arrowhead) (C) Patchy hyperintensity on T2-weighted image (arrow). (D) There is heterogeneous enhancement on arterial (arrow). (E) On venous phase there are central nonenhancing areas (arrow) suggestive of necrosis.
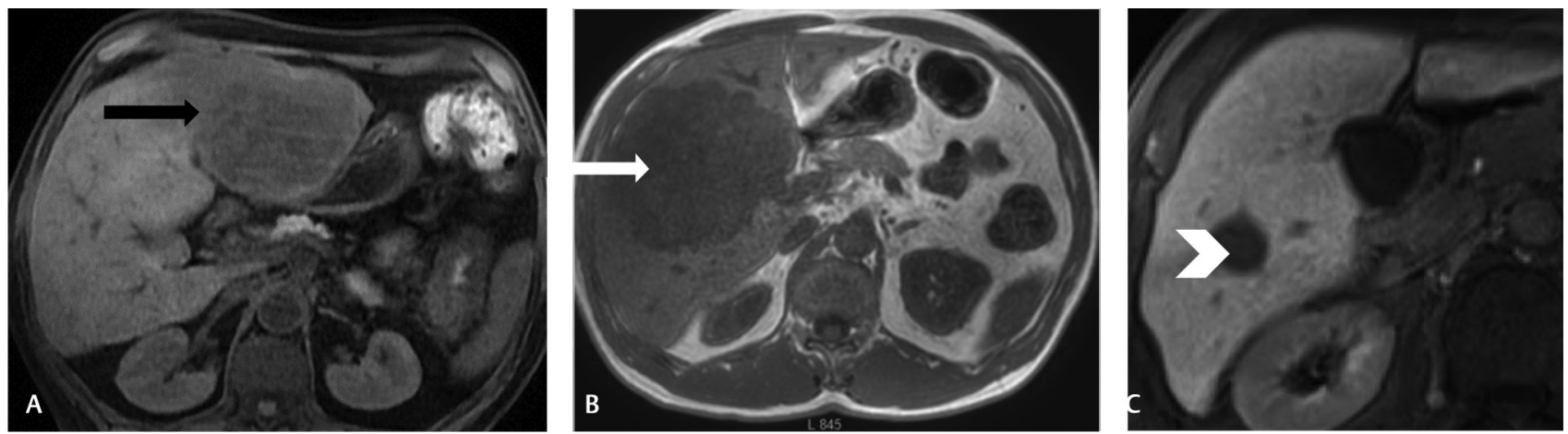

Fig. 14 Axial T1-weighted images. (A) Lesion is considered to have minor hypointensity (arrow) if intensity is between the level of the liver and spleen, (B) moderately hypointense (arrow) if the intensity is comparable to the spleen, (C) markedly hypointense (white arrowhead) if the intensity is comparable to the cerebrospinal fluid.
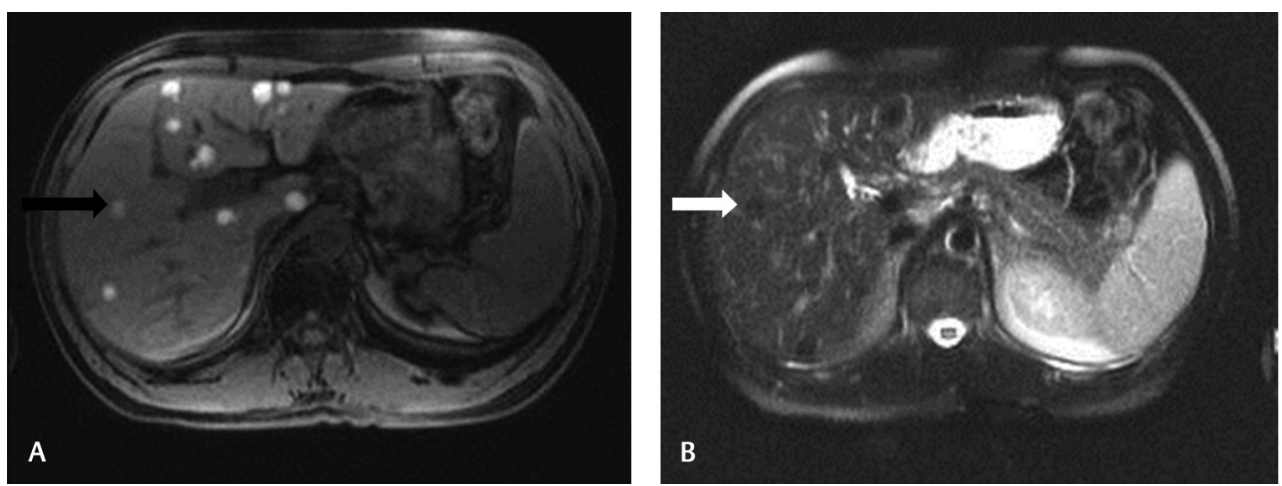

Fig. 15 MRI of the liver: (A) T1-weighted images showing multiple T1 hyperintense lesion in liver and (B) These lesions are hypointense on T2 weighted images consistent with malignant melanoma metastases.

In patients who cannot receive gadolinium-based contrast agents, diffusion-weighted (DW)-MRI has the potential to be a reasonable alternative technique to contrast-enhanced imaging (-Fig. 19).54,55 In one study, addition of DW MR imaging to mangafodipir trisodium contrast-enhanced MR imaging significantly improved the diagnostic accuracy for 

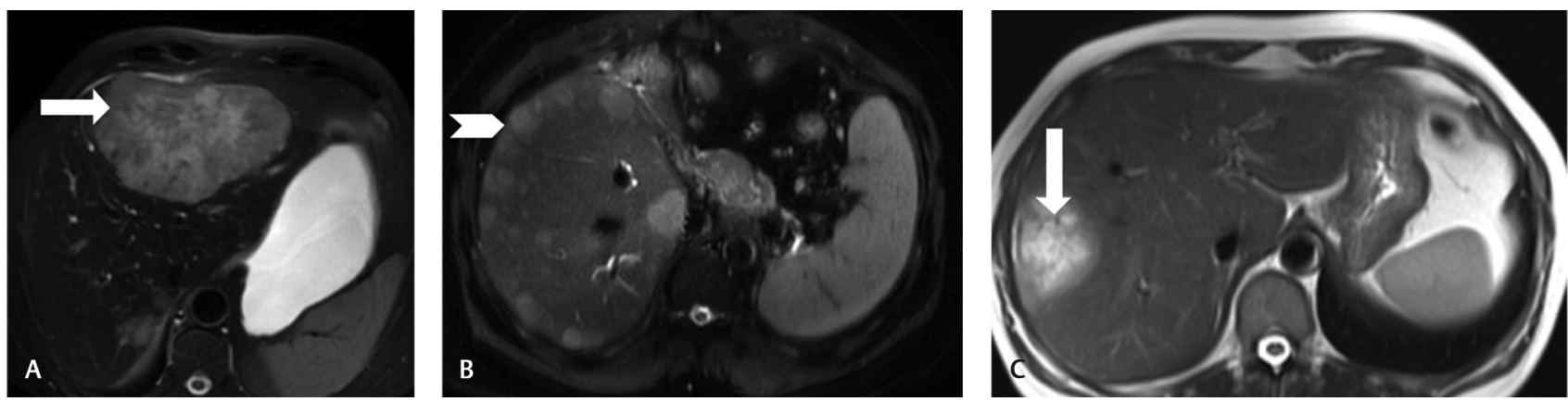

Fig. 16 MRI with liver-specific contrast agent. (A) Lesion shows patchy hyperintensity on T2-weighted images (B) There is intense uptake of contrast during arterial phase suggestive of vascular metastases. (C) Lesion takes up contrast during the delayed phase (arrow). High signal of delayed phase may be seen in cholangiocarcinoma or Follicular nodular hyperplasia and certain hepatocellular carcinomas.

detection of colorectal liver metastases compared with either technique alone..$^{54}$ DW MR imaging was found to be of value

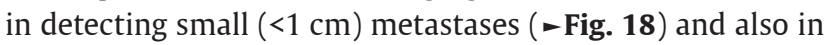
revealing lesions close to the edge of the liver, as these lesions are easily overlooked on mangafodipir trisodium-enhanced T1-weighted MR images. ${ }^{54}$

Differentials to consider for liver metastases are:

- Small fast filling hemangiomas: they appear markedly hyperintense on T2 images and show no evidence of washout which is usually seen in metastases (-Fig. 20).

- Small FNH)may not have central scars and may show homogeneous increased enhancement in the hepatic arterial dominant phase and tend to become isointense with the remaining liver parenchyma in later phases. However, FNH shows uptake in delayed images if liver-specific contrast agents are used.

- Vascular anomalies including collaterals, shunts, and fistula demonstrate structural enhancing vascular abnormalities that show communication and continuation with hepatic arteries, hepatic veins, and portal veins. Metastases tend to be rounded and shunts tend to be linear-shaped or wedge-shaped.

- Areas showing transient vascular enhancement (THAD) do not show precontrast T1-WI or T2-WI, or diffusion-weighted imaging abnormalities.

Hepatocellular carcinoma (HCC) shows hypervascular pattern in arterial phase with washout in subsequent phases and appears as filling defects in hepatobiliary phase. In addition, there are several ancillary features favoring the diagnosis of HCC. ${ }^{56}$ Approximately $70 \%$ of lesions exhibit a tumor capsule or pseudo capsule, which appears as a delayed enhancing rim, and the appearance of the capsule has been shown to be an important predictor of HCC.

Intrahepatic mass-forming cholangiocarcinoma (ICC) may result in capsular retraction, peripheral ductal dilatation and demonstrates typical (77\%) peripheral rim like arterial enhancement with delayed progressive and concentric fill-in enhancement owning to fibrotic tissue. ${ }^{57}$ On hepatic biliary phase images, most ICCs (96\%) show low signal intensity.

\section{PET-CT}

PET-CT combines the functional component of 18 fluorodeoxyglucose (FDG) uptake indicating active tissue with the anatomical advantage of CT. Liver metastases from several primaries show uptake on 18 FDG PET particularly those from colorectal, breast, and lung primaries.

Only a selected number of patients with liver metastases appear to be candidates for surgical resection and ablation techniques. Most patients prove to have unrespectable disease; PET-CT plays an important role in making this distinction.

In colorectal cancers, liver is the main site of metastases. Liver metastases show increased uptake with standard uptake value greater than 3.5 ( - Fig. 21).

The sensitivity and specificity of PET-CT for the detection of hepatic metastases from colorectal cancer (CRC) is 88 to $96 \%$ and 75 to $96 \%$, respectively. ${ }^{55,56}$ A subgroup analysis showed a slightly higher sensitivity for detection of non-CRC metastases (94 vs. 98\%) but an equal specificity of $75 \%{ }^{56,58}$

Two large meta-analysis by Kinkel et al ${ }^{59}$ found FDG PET to be a very sensitive (90-94.6\%) imaging modality in the detection of liver metastases resulting from colorectal, gastric, and esophageal primary cancers.

A study by Grassetto et $\mathrm{l}^{60}$ evaluated 43 patients with a known solitary liver metastasis and in 12 of 43 patients (28\%), FDG PET-CT resulted in restaging and a change in therapy. The authors stated that the addition of FDG PET-CT in the assessment of patients with liver metastasis could have a significant impact on the staging and selection of candidates for liver metastasis resection and ablation.

When comparing FDG PET-CT to other conventional imaging, in a retrospective review by Kong et al ${ }^{61,62}$ of 65 patients with colorectal carcinoma, FDG PET-CT identified unexpected extrahepatic disease not detected on contrastenhanced $\mathrm{CT}$, leading to a change in surgical management in $17 \%$ of the cases.

Thus, the ability of FDG PET-CT to detect extrahepatic disease or occult intrahepatic metastases that is not evident on conventional imaging is crucial in selecting patients who are suitable for ablative or surgical therapy and impacts patient management. FDG PET-CT is particularly effective for 

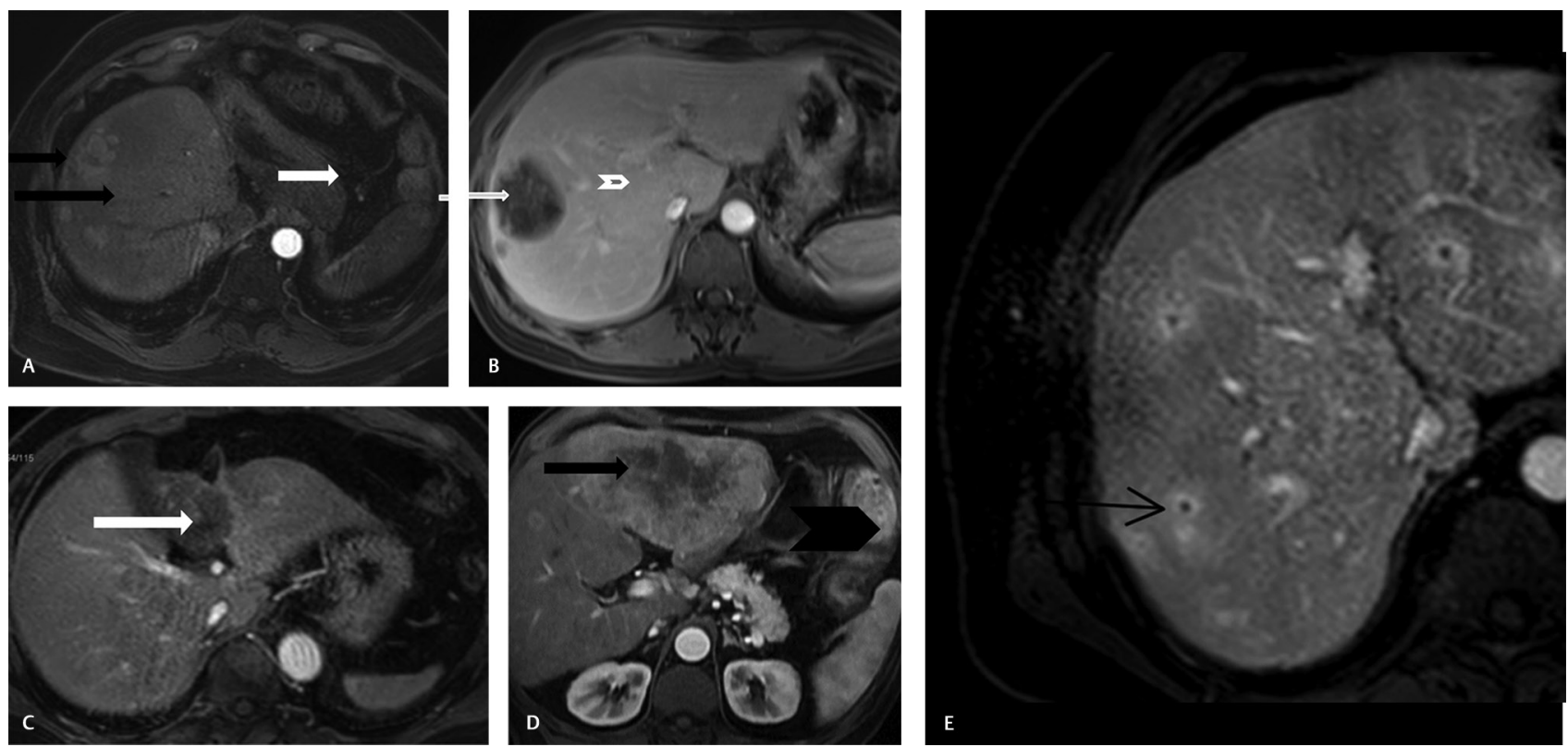

Fig. 17 Different enhancement pattern of hepatic metastatic lesion. (A) Homogenous-contrast enhancement (black arrow)-hypervascular metastases. (B) Heterogeneous pattern of enhancement (white arrow) in lesions-nonspecific, seen commonly in hypervascular metastases. (C) No enhancement of lesion (white arrow)-hypovascular metastases. (D) Peripheral ring pattern (black arrow)-specific enhancement pattern for liver metastases. (E) Multiple target like lesion (black arrow) in liver-metastatic deposit.
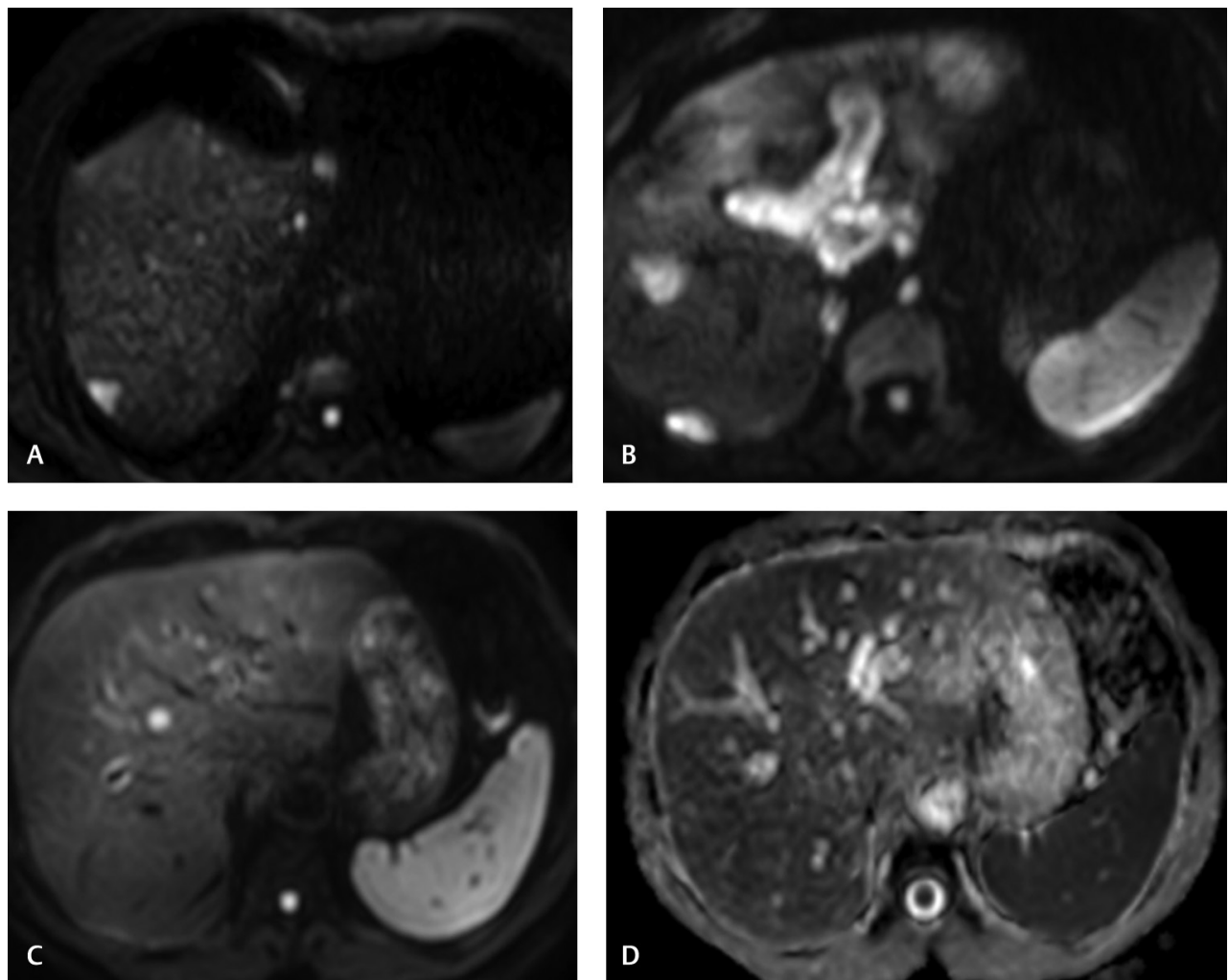

Fig. 18 Magnetic resonance abdomen, diffusion-weighted images (A, B) showing multiple small bright foci in keeping with metastasis (C, D) showing small foci of diffusion-restricted lesion and low signal on apparent diffusion coefficient maps (D) suggestive of metastasis.

colorectal cancer, in identification of additional hepatic and extrahepatic metastases, and frequently upstaging the tumor stage and affecting management. ${ }^{63}$

FDG PET-CT helps for follow-up after treatment of liver metastases to assess both for efficacy of treatment and for recurrence. ${ }^{64}$
FDG-PET may fail to demonstrate small $(<1 \mathrm{~cm})$ liver metastases and also metastases that are FDG negative like mucinous carcinoma, renal and prostatic metastases ${ }^{65-67}(\mathbf{- F i g . ~ 2 2}$ ).

The sensitivity of FDG PET for detecting metastases is generally lowered after treatment due to decreased metabolism and FDG uptake. 


\begin{tabular}{|l|l|l|}
\hline & b0 & High b \\
\hline $\begin{array}{l}\text { Benign Lesion } \\
\text { (E.g. cystic-necrotic lesion) }\end{array}$ & \\
\hline $\begin{array}{l}\text { Malignant Lesion } \\
\text { (E.g. Metastasis) }\end{array}$ & \\
\hline $\begin{array}{l}\text { T2 shine through } \\
\text { (E.g. cyst-hemangioma) }\end{array}$ & \\
\hline
\end{tabular}

Fig. 19 Showing diffusion characteristics of benign and malignant lesions. Bright DW/high ADC: cyst, hemangioma, necrotic/or treated malignancy. Bright DW/low ADC: malignancy, HCC/dysplastic nodules in chronic liver disease, abscess. Intermediate DW/ADC: FNH, adenoma. DW, diffusion-weighted; FNH, focal nodular hyperplasia; HCC, hepatocellular carcinoma. ADC, apparent diffusion coefficient.
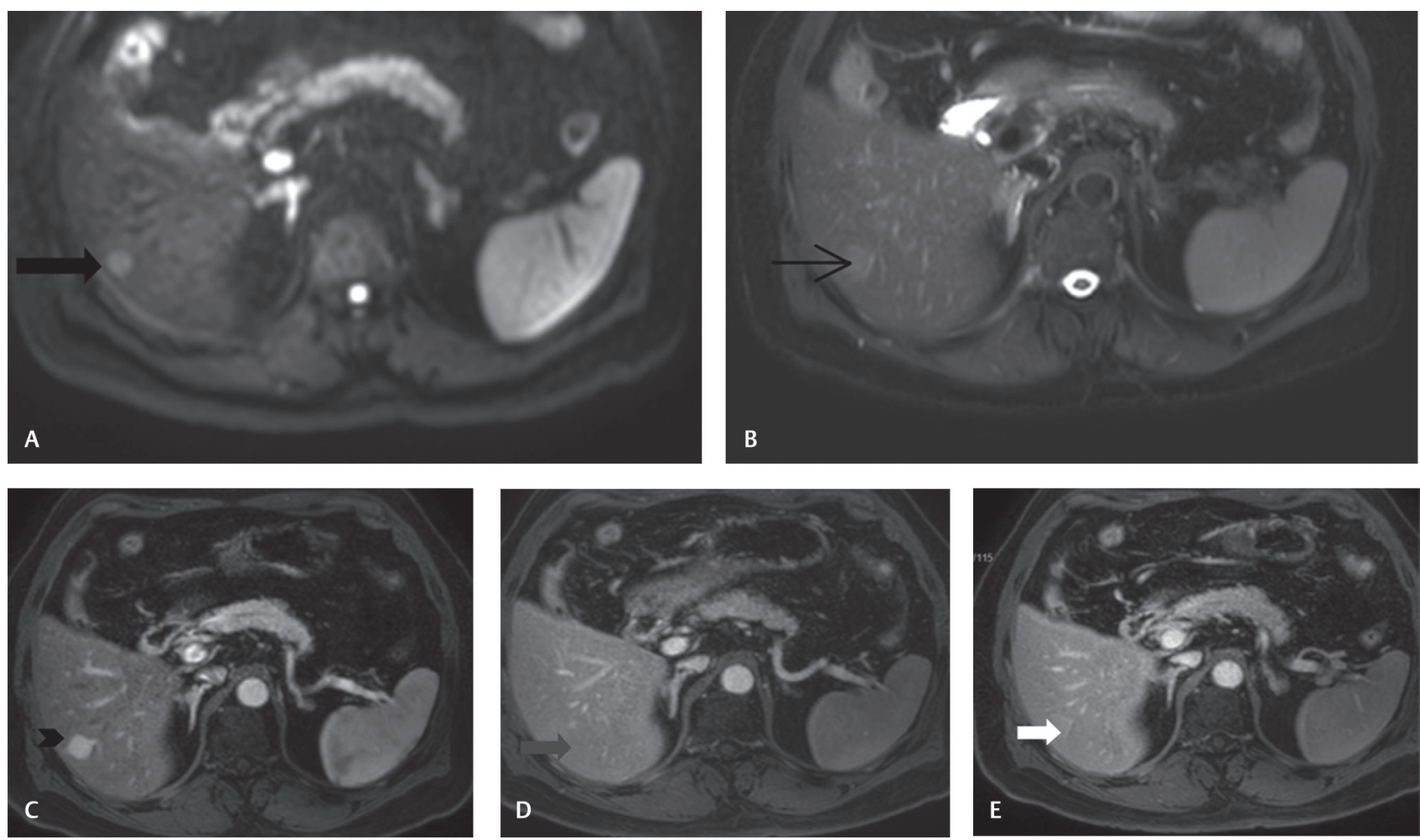

Fig. 20 Magnetic resonance abdomen, diffusion-weighted images (A) showing small bright foci (black arrow) with hyperintense signal (black arrow) on T2-weighted images (B) and show avidly enhancing lesion (black arrowhead) on arterial phase (C) and progressive enhancement (blue arrowhead) on venous phase (D), show isointense (white arrow) to liver parenchyma in delayed phase (E).

\section{Discussion}

FDG PET easily detects liver metastases, as they are FDG avid. This sensitivity is equal or superior to CT. FDG PET detects unsuspected extrahepatic disease leading to upstaging in disease and change in treatment course. FDG PET improves patient selection for various treatment options, and helps in posttreatment follow-up.

\section{Imaging in Posttreatment Assessment of Liver Metastases}

Multiple treatment options are available for the treatment of liver metastases, for example, surgical, chemotherapy, chemo/radioembolization, RFA/MWA, etc. CT is commonly used for the assessment of treatment response (-Fig. 23).

The size of the treated lesion following ablation is often larger than the size of the original lesion. This is the result of inclusion of a rim of normal liver in the treatment area with hyperattenuation due to hemorrhage and coagulative necrosis which is best seen on the noncontrast $\mathrm{CT}^{68}$

MRI demonstrates coagulation necrosis after RFA as intermediate to high signal to-liver parenchyma on T1-weighted and low signal on T2-weighted images (-Fig. 24). A T2 hyperintense rim around the ablated area may be seen that may be due to edema from thermal injury. 

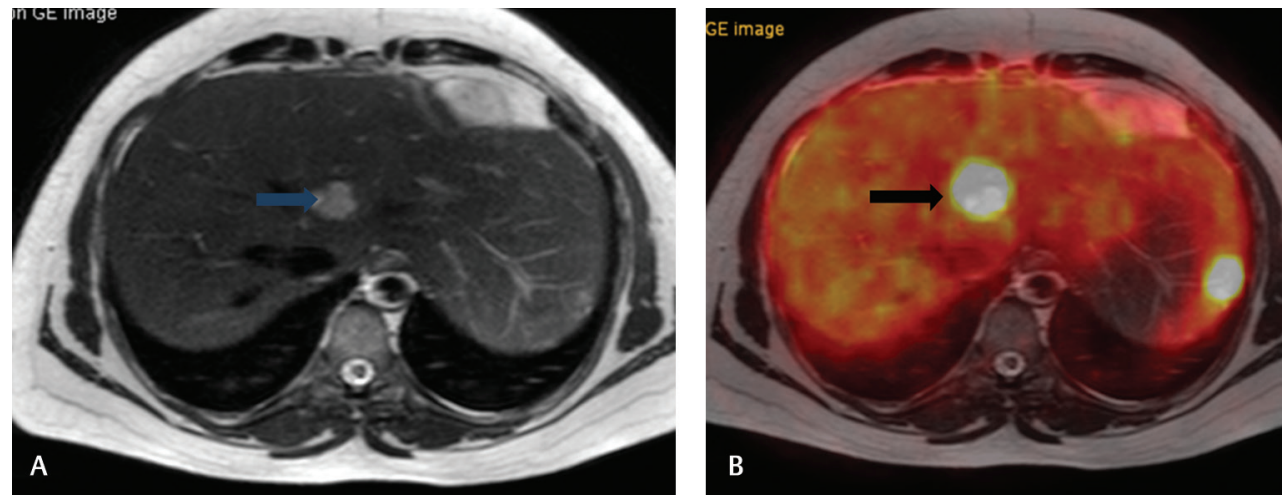

Fig. 21 (A) Axial images of T2-weighted images of the liver showing hyperintense liver lesion (blue arrow); (B) FDG uptake seen on PET images (black arrow) suggestive of hypervascular lesion. FDG fluorodeoxyglucose; PET, positron emission tomography.
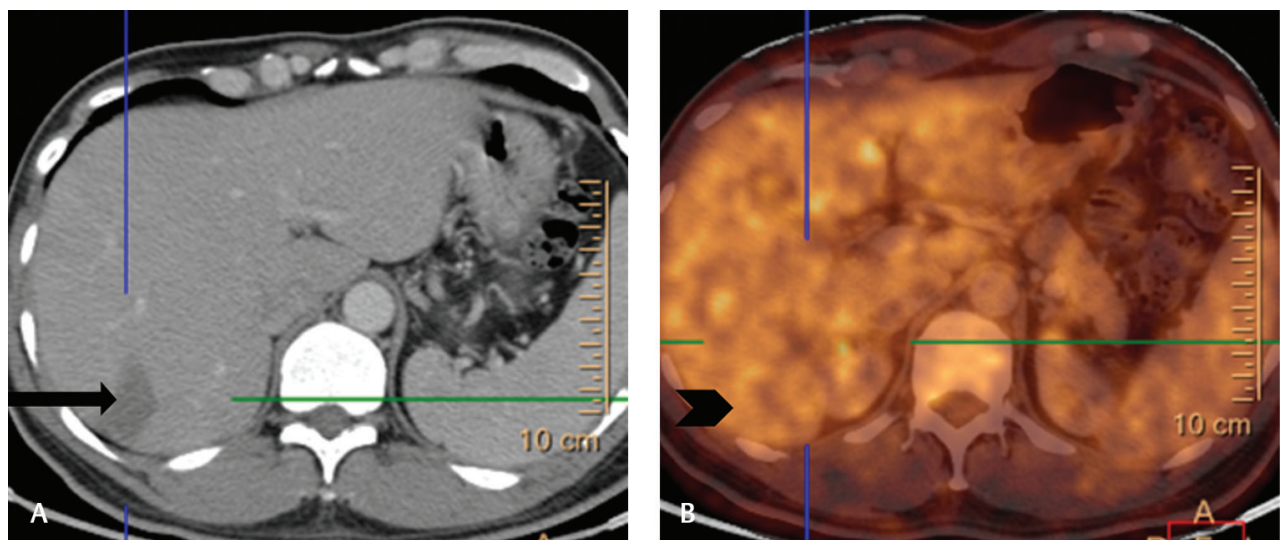

Fig. 22 (A) Axial images of contrast enhanced CT of the liver (arterial phase) showing hypodense liver lesion (black arrow). (B) No FDG uptake seen on PET images (black arrowhead) suggestive of hypovascular lesion. FDG fluorodeoxyglucose; PET, positron emission tomography.
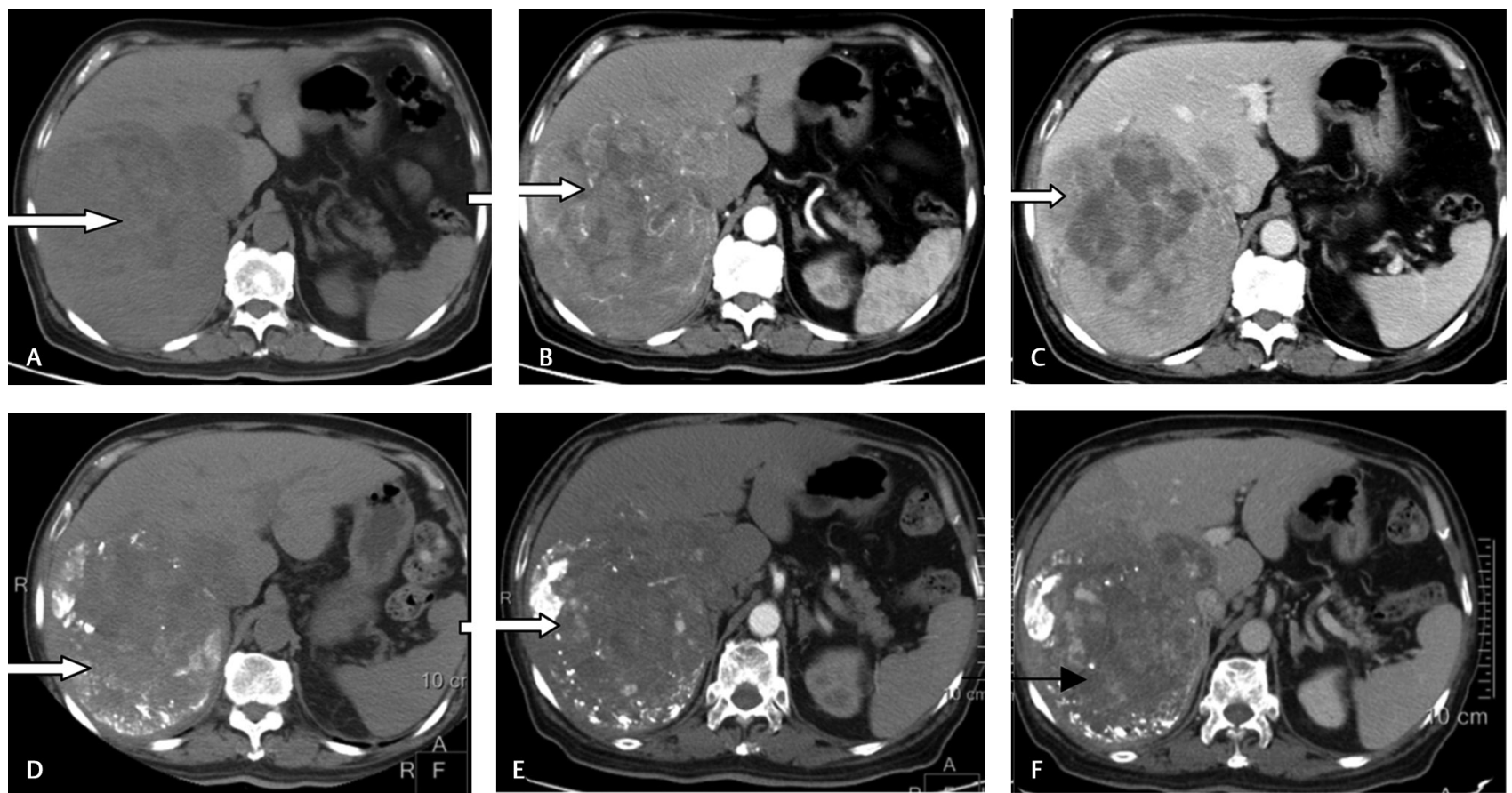

Fig. 23 Post-transarterial chemoembolization changes. (A) Preembolization plain CT axial sections of liver showing a large hypodense lesion in the right lobe of the liver (white arrow). (B) Heterogeneous enhancement is seen on the arterial phase (bold white arrow). (C) Delayed phase demonstrates washout out (white arrowheads). (D) Postembolization plain CT axial sections of liver in plain CT showing the hypodense lesion in the right lobe of liver with peripheral hyperdensity representing lipiodol (black arrow). (E) Arterial phase shows decreased enhancement compared with the pretreatment study (bold black arrow). (F) Delayed phase minimal washout out. CT, computed tomography. 
On MR posttreatment liver metastases may appear heterogenous due to hemorrhage or necrosis on unenhanced images.

\section{Postcontrast CT/MR Imaging}

On postcontrast $\mathrm{CT} / \mathrm{MR}$ imaging nonenhancement suggests good response ( - Fig. 25A).

Ring enhancement is a common phenomenon due to thermal injury of the normal adjacent liver parenchyma (-Fig. 25B).

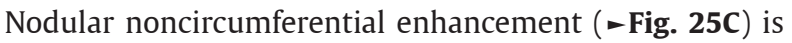
suggestive of tumor. ${ }^{69}$

Both CT and MRI demonstrated a similar capability to detect recurrence of liver metastases within 4 months of treatment, with a slight advantage to MRI. ${ }^{70}$

For FDG-avid lesions, FDG PET-CT is an important diagnostic modality for the assessment of treatment response; a previously FDG avid lesion shows no FDG uptake in the ablation zone after a successful ablation ( - Fig. 26).

In patients who have undergone systemic chemotherapy, CECT is considered superior to FDG PET. This is thought to be secondary to reduced metabolic activity leading to reduced uptake compared with background uptake and a reduction in the size of the lesion below the resolution of PET. ${ }^{71}$

Nonenhancement and decrease in the size of the lesions on the CECT following chemotherapy suggest a good response.

Heterogeneously enhancing lesions may show a reduction in the enhancement and a marked decrease in tumor density on non-contrast CT without decrease in size ${ }^{72}$ due to extensive cystic or myxoid degeneration. ${ }^{73}$

Some cases may show transient increase in size owing to cystic change and intratumoral hemorrhage. ${ }^{74}$

Nodular noncircumferential enhancement with increase in size suggests resistance to treatment. New enhancing
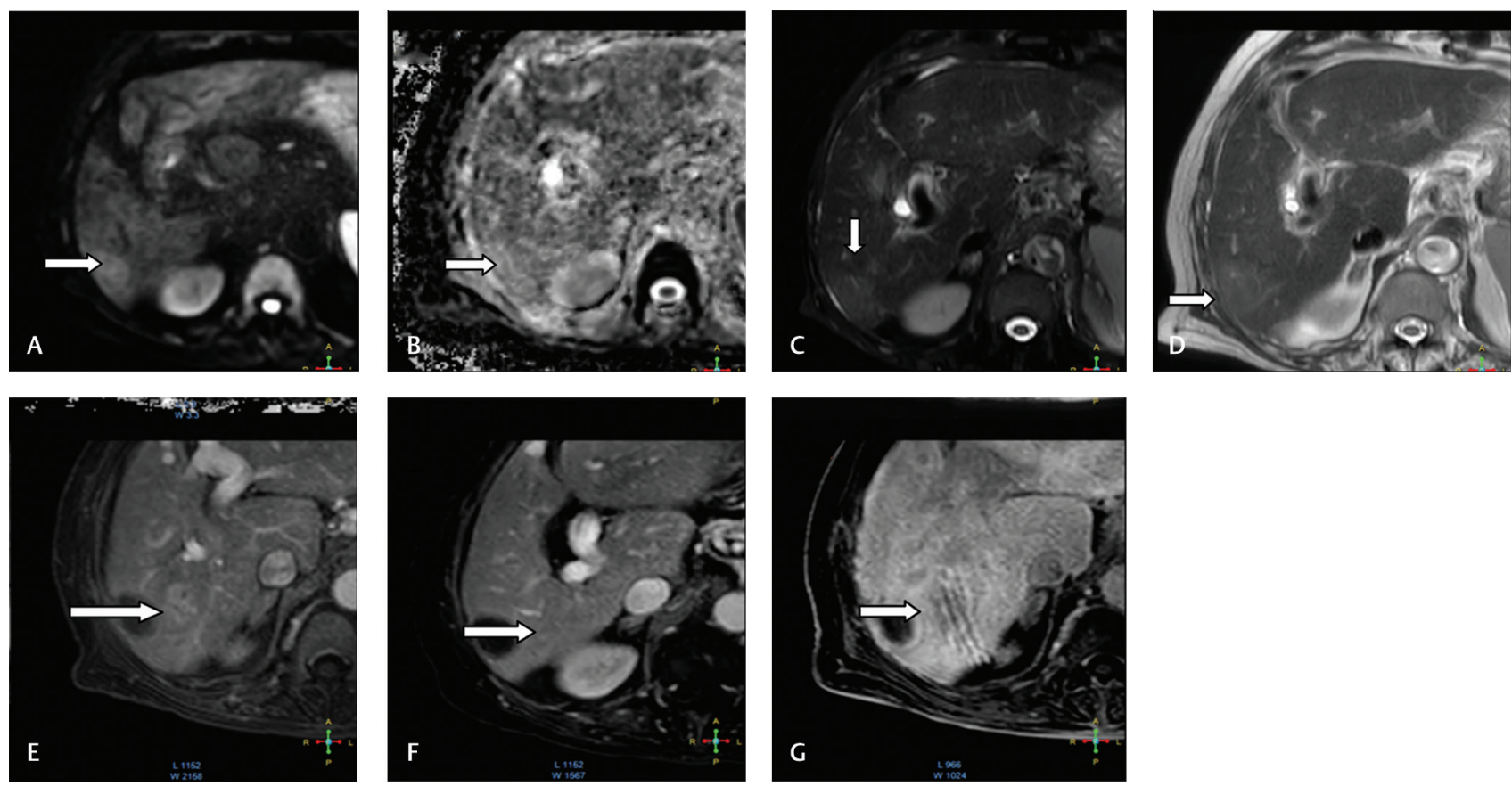

Fig. 24 Post-transarterial chemoembolization magnetic resonance imaging appearances (refer $\mathbf{- F i g . ~ 9 ) . ~ ( A ) ~ A x i a l ~ d i f f u s i o n - w e i g h t e d ~ a n d ~}$ (B) ADC images showing no diffusion restriction. (C and D) Mild hyperintense signal on T2-weighted images (white arrow). Post contrast images show no enhancement (white arrowheads) on arterial (E), Venous (F), delayed phases $(\mathbf{G})$.
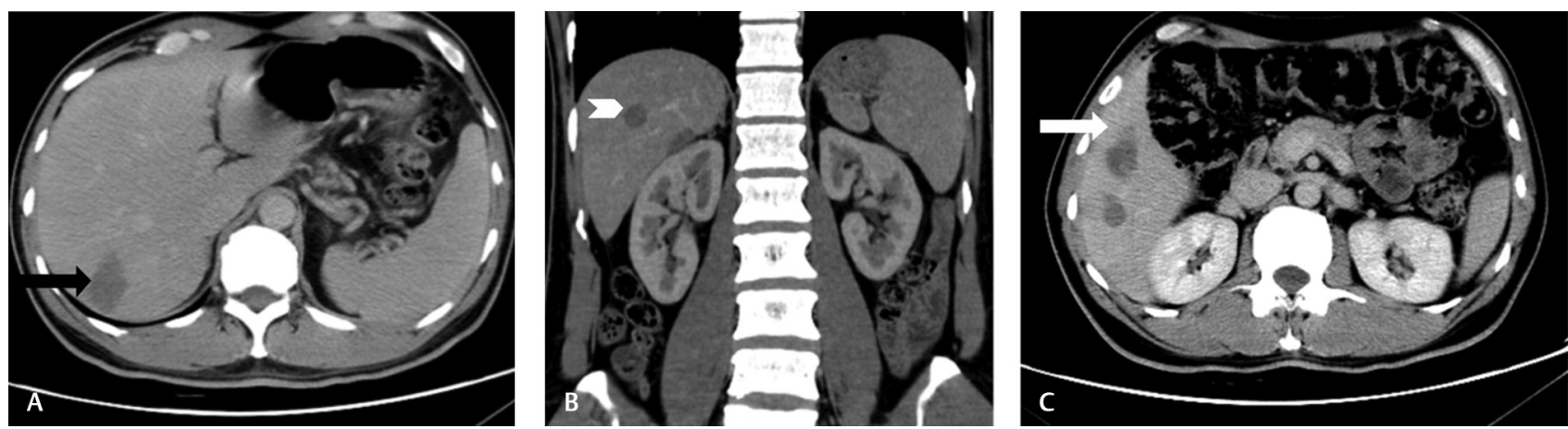

Fig. 25 Post-radiofrequency ablation CT findings (A) showing nonenhancing hypodense area (black bold arrow)-coagulation necrosis. (B) Hypodense lesion with peripheral wall enhancement (white arrowhead)-physiological reaction of normal liver parenchyma to heat damage which disappears in a month. (C) Hypodense lesion with eccentric wall enhancement (white bold arrow)-residual lesion to be suspected. CT, computed tomography. 

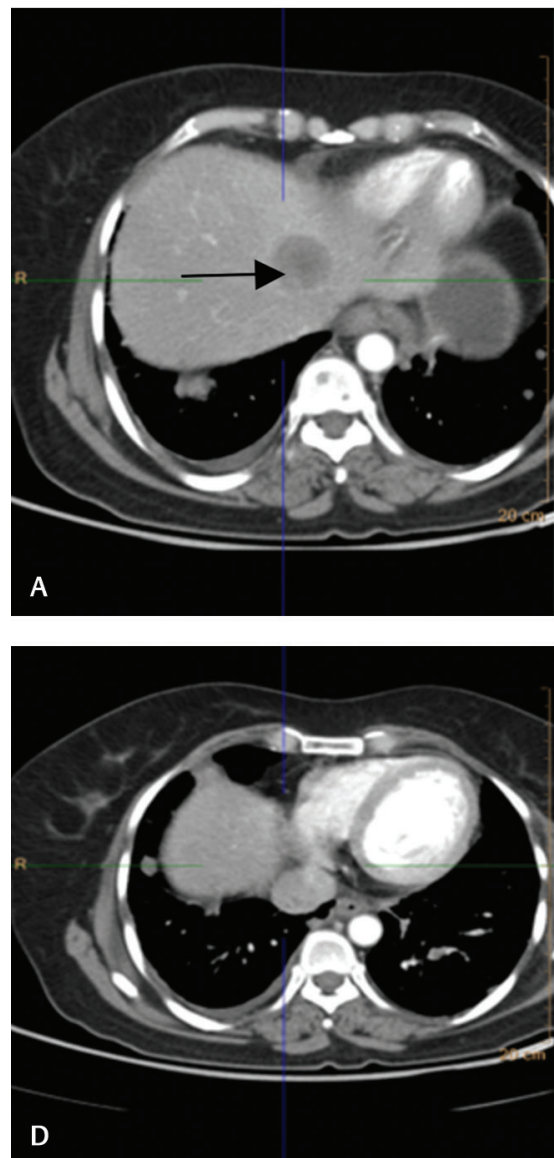
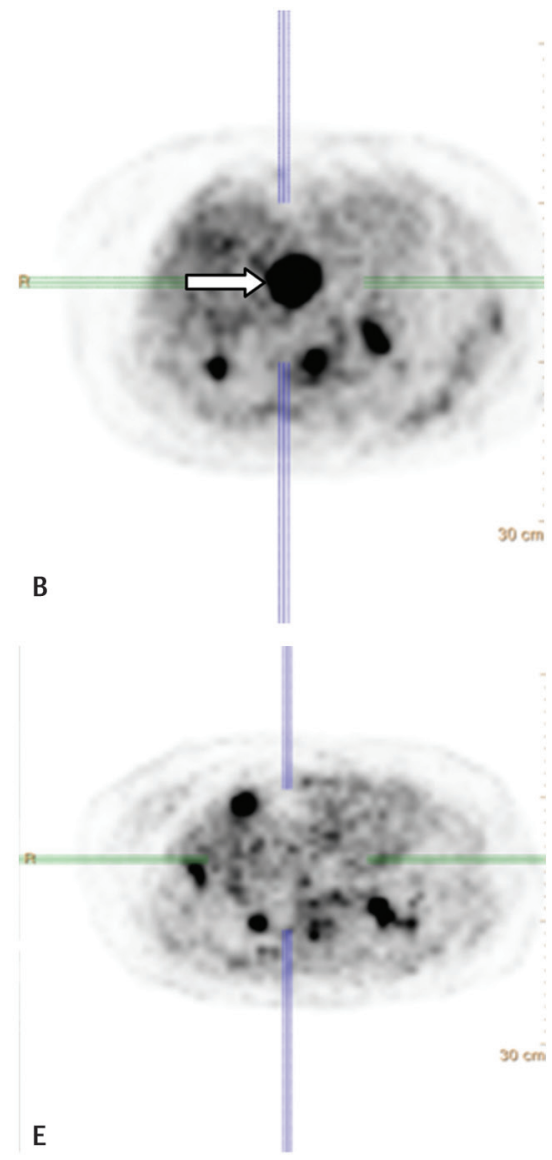
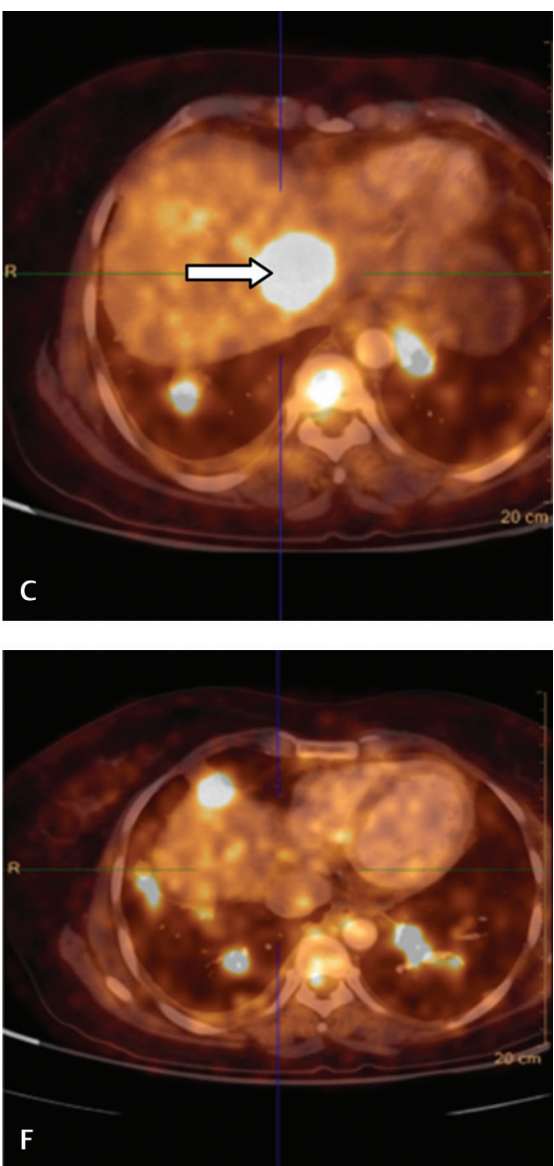

Fig. 26 (A) Axial images of CECT of the liver (arterial phase) showing hypodense liver lesion with peripheral enhancement (black arrow). (B, C) FDG uptake seen on PET images (white arrow). Multiple lung metastases are present with FDG uptake (white arrowheads). Postablation treatment axial images of the liver (arterial phase) showing hypodense liver lesion with no enhancement (black arrow). (B, C), No FDG uptake seen on PET images (white arrow). Multiple lung metastases are present with FDG uptake (white arrowheads). FDG, fluorodeoxyglucose; PET, positron emission tomography.

nodules in cystic mass referred to as nodules within cyst appearance also suggest nonresponse. ${ }^{76}$

In our institute we use MRI to assess postablation patients as an absence of any contrast enhancement effectively rules out recurrence.

The treatment of choice for gastrointestinal stromal tumor is surgery, but preoperative imatinib is useful in reducing tumor burden further helping in improving the resectability. Treatment with imatinib also reduces intraoperative risk of hemorrhage. ${ }^{73}$

\section{Conclusion}

Advances in imaging technology have significantly improved our ability to detect and characterize metastatic liver disease and assess the tumor burden.

MDCT is primarily used for initial diagnosis of suspected liver metastases during staging investigation following detection of the primary malignancy; and also for surveillance following treatment, as MDCT is widely available and also allows for assessment of extrahepatic disease.

For intrahepatic metastases, the sensitivities of FDG PET-CT and MDCT are equivalent. For extrahepatic disease FDG PET-CT is superior.
For presurgical assessment of liver metastases, MRI is the preferred modality due to its ability to identify small, that is, $<1 \mathrm{~cm}$ metastases, its higher contrast resolution, and its better characterization of liver lesions.

For assessment of treatment response both CT and MRI demonstrate a similar capability to detect recurrence of liver metastases within the early posttreatment stage with a slight advantage to MRI.

Finally, the modality to be used should be based on clinical expertise and institutional practice.

\section{Conflict of Interest}

None declared.

\section{References}

1 Schwartz SI, Liver. In: Schwartz SI, Shires TG, Spencer FC, et al., eds. Principles of Surgery. 7th ed. New York, NY: McGraw-Hill, Health Professions Division; 1999:1411

2 Jones EC, Chezmar JL, Nelson RC, Bernardino ME. The frequency and significance of small (less than or equal to $15 \mathrm{~mm}$ ) hepatic lesions detected by CT. Am J Roentgenol 1992;158 (3):535-539

3 Schwartz LH, Gandras EJ, Colangelo SM, Ercolani MC, Panicek DM. Prevalence and importance of small hepatic lesions found at CT in patients with cancer. Radiology 1999;210(1):71-74 
4 Thyavihally YB, Mahantshetty U, Chamarajanagar RS, Raibhattanavar SG, Tongaonkar HB. Management of renal cell carcinoma with solitary metastasis. World J Surg Oncol 2005;3:48

5 Kamel IR, Kruskal JB, Warmbrand G, Goldberg SN, Pomfret EA, Raptopoulos V. Accuracy of volumetric measurements after virtual right hepatectomy in potential donors undergoing living adult liver transplantation. AJR Am J Roentgenol 2001;176(2):483-487

6 Expert Panel on Gastrointestinal Imaging; Kaur H, Hindman NM, Al-Refaie WB. Suspected liver metastases. J Am Coll Radiol 2017;14(5):S314-S325

7 Floriani I, Torri V, Rulli E, et al. Performance of imaging modalities in diagnosis of liver metastases from colorectal cancer: a systematic review and meta-analysis. J Magn Reson Imaging 2010;31(1):19-31

8 Albrecht T, Blomley MJ, Burns PN, et al. Improved detection of hepatic metastases with pulse-inversion US during the liver-specific phase of SHU 508A: multicenter study. Radiology 2003;227(2):361-370

9 Bartolotta TV, Midiri M, Quaia E, et al. Liver haemangiomas undetermined at grey-scale ultrasound: contrast-enhancement patterns with SonoVue and pulse-inversion US. Eur Radiol 2005;15(4):685-693

10 Celli N, Gaiani S, Piscaglia F, et al. Characterization of liver lesions by real-time contrast-enhanced ultrasonography. Eur J Gastroenterol Hepatol 2007;19(1):3-14

11 Dietrich CF, Kratzer W, Strobe D, et al. Assessment of metastatic liver disease in patients with primary extrahepatic tumors by contrast-enhanced sonography versus CT and MRI. World J Gastroenterol 2006;12(11):1699-1705

12 Dietrich CF, Mertens JC, Braden B, Schuessler G, Ott M, Ignee A. Contrast-enhanced ultrasound of histologically proven liver hemangiomas. Hepatology 2007;45(5):1139-1145

13 Lanka B, Jang HJ, Kim TK, Burns PN, Wilson SR. Impact of contrast-enhanced ultrasonography in a tertiary clinical practice. J Ultrasound Med 2007;26(12):1703-1714

14 Luo W, Numata K, Morimoto M, et al. Focal liver tumors: characterization with 3D perflubutane microbubble contrast agent-enhanced US versus 3D contrast-enhanced multidetector CT. Radiology 2009;251(1):287-295

15 Trillaud H, Bruel JM, Valette PJ, et al. Characterization of focal liver lesions with SonoVue-enhanced sonography: international multicenter-study in comparison to CT and MRI. World J Gastroenterol 2009;15(30):3748-3756

16 Vialle R, Boucebci S, Richer JP, et al. Preoperative detection of hepatic metastases from colorectal cancer: prospective comparison of contrast-enhanced ultrasound and multidetector-row computed tomography (MDCT). Diagn Interv Imaging 2016;97(9):851-855

17 Leoni S, Piscaglia F, Golfieri R, et al. The impact of vascular and nonvascular findings on the noninvasive diagnosis of small hepatocellular carcinoma based on the EASL and AASLD criteria. Am J Gastroenterol 2010;105(3):599-609

18 Wilson SR, Kim TK, Jang HJ, Burns PN. Enhancement patterns of focal liver masses: discordance between contrast-enhanced sonography and contrast-enhanced CT and MRI. AJR Am J Roentgenol 2007;189(1):W7-W12

19 Parker GA, Lawrence W Jr, Horsley JS III. et al. Intraoperative ultrasound of the liver affects operative decision making. Ann Surg 1989;209(5):569-576, discussion 576-577

20 Marcal LP, Patnana M, Bhosale P, Bedi DG. Intraoperative abdominal ultrasound in oncologic imaging. World J Radiol 2013;5(3):51-60

21 Sietses C, Meijerink MR, Meijer S, van den Tol MP. The impact of intraoperative ultrasonography on the surgical treatment of patients with colorectal liver metastases. Surg Endosc 2010;24(8):1917-1922
22 Kruskal JB, Kane RA. Intraoperative US of the liver: techniques and clinical applications. Radiographics 2006;26(4):1067-1084

23 Silas AM, Kruskal JB, Kane RA. Intraoperative ultrasound. Radiol Clin North Am 2001;39(3):429-448

24 D’Onofrio M, Vecchiato F, Faccioli N, Falconi M, Pozzi Mucelli R. Ultrasonography of the pancreas. 7. Intraoperative imaging. Abdom Imaging 2007;32(2):200-206

25 Penna C, Nordlinger B. Surgery of liver metastases from colorectal cancer: new promises. Br Med Bull 2002;64:127-140

26 Conlon R, Jacobs M, Dasgupta D, Lodge JP. The value of intraoperative ultrasound during hepatic resection compared with improved preoperative magnetic resonance imaging. Eur J Ultrasound 2003;16(3):211-216

27 Wagnetz U, Atri M, Massey C, Wei AC, Metser U. Intraoperative ultrasound of the liver in primary and secondary hepatic malignancies: comparison with preoperative 1.5-T MRI and 64-MDCT. AJR Am J Roentgenol 2011;196(3):562-568

28 Kartalis N, Brismar TB, Mihocsa L, Isaksson B, Albiin N. The added value of contrast-enhanced ultrasound in patients with colorectal cancer undergoing preoperative evaluation with extensive gadobenate dimeglumine liver MRI. Eur Radiol 2011;21(10):2067-2073

$29 \mathrm{Kim} \mathrm{HO}$, Kim SK, Son BH, et al. Intraoperative radiofrequency ablation with or without tumorectomy for hepatocellular carcinoma in locations difficult for a percutaneous approach. Hepatobiliary Pancreat Dis Int 2009;8(6):591-596

30 Crucitti A, Danza FM, Antinori A, et al. Radiofrequency thermal ablation (RFA) of liver tumors: percutaneous and open surgical approaches. J Exp Clin Cancer Res 2003;22(4, Suppl): 191-195

31 Soyer P, Poccard M, Boudiaf M, et al. Detection of hypovascular hepatic metastases at triple-phase helical CT: sensitivity of phases and comparison with surgical and histopathologic findings. Radiology 2004;231(2):413-420

32 Kuszyk BS, Bluemke DA, Urban BA, et al. Portal-phase contrast-enhanced helical CT for the detection of malignant hepatic tumors: sensitivity based on comparison with intraoperative and pathologic findings. AJR Am J Roentgenol 1996;166(1):91-95

33 Bonaldi VM, Bret PM, Reinhold C, Atri M. Helical CT of the liver: value of an early hepatic arterial phase. Radiology 1995;197(2):357-363

34 Hollett MD, Jeffrey RB, Jr. Nino-Murcia M, Jorgensen MJ, Harris DP. Dual-phase helical CT of the liver: value of arterial phase scans in the detection of small $(<$ or $=1.5 \mathrm{~cm})$ malignant hepatic neoplasms. AJR Am J Roentgenol 1995;164(4):879-884

35 Sica GT, Ji H, Ros PR. CT and MR imaging of hepatic metastases. AJR Am J Roentgenol 2000;174(3):691-698

36 Wicherts D, de Haas R, van Kessel C, Bisschops R, Takahara T, van Hillegersberg $\mathrm{R}$, et al. Incremental value of arterial and equilibrium phase compared to hepatic venous phase CT in the preoperative staging of colorectal liver metastases: an evaluation with different reference standards. Eur J Radiol 2011;77(2):305-311

37 Detection of hypovascular hepatic metastases at triplephase helical CT: sensitivity of phases and comparison with surgical and histopathologic findings. Radiology. 2004;231(2):413-420

38 Honda Y, Higaki T, Higashihori $\mathrm{H}$, et al. Re-evaluation of detectability of liver metastases by contrast-enhanced CT: added value of hepatic arterial phase imaging. Jpn J Radiol 2014;32(8):467-475

39 Silverman P. Liver metastases: imaging considerations for protocol development with multislice CT (MSCT). Cancer Imaging 2006;6:175-181 
40 Ko Y, Kim J, Park JK, et al. Limited detection of small ( $\leq 10 \mathrm{~mm}$ ) colorectal liver metastasis at preoperative CT in patients undergoing liver resection. PLoS One 2017;12(12):e0189797

41 Radiology Key. Liver metastases. 2019. Available at: https:// radiologykey.com/liver-metastases-2. Accessed Nov 12, 2019

42 Soyer P, Bluemke DA, Vissuzaine C, Beers BV, Barge J, Levesque M. CT of hepatic tumors: prevalence and specificity of retraction of the adjacent liver capsule. AJR Am J Roentgenol 1994;162(5):1119-1122

43 Apicella PL, Mirowitz SA, Weinreb JC. Extension of vessels through hepatic neoplasms: MR and CT findings. Radiology 1994;191(1):135-136

44 Seale MK, Catalano OA, Saini S, Hahn PF, Sahani DV. Hepatobiliary-specific MR contrast agents: role in imaging the liver and biliary tree. Radiographics 2009;29(6):1725-1748

45 Baum S. Hepatic arteriography. In: Baum S, ed Abram's Angiography 4th ed. Boston: Little Brown; 1997:1433-1456

46 Nino-Murcia M, Olcott EW, Jeffrey RB Jr, Lamm RL, Beaulieu CF, Jain KA. Focal liver lesions: pattern-based classification scheme for enhancement at arterial phase CT. Radiology 2000;215(3):746-751

47 Semelka RC, Braga L, Armao D, et al. Liver. In: Semelka RC, ed. Abdominal-Pelvic MRI. 1st ed. New York, NY: Wiley-Liss; 2002:101-134

48 Mahfouz AE, Hamm B, Wolf KJ. Peripheral washout: a sign of malignancy on dynamic gadolinium-enhanced MR images of focal liver lesions. Radiology 1994;190(1):49-52

49 Danet IM, Semelka RC, Leonardou P, et al. Spectrum of MRI appearances of untreated metastases of the liver. AJR Am J Roentgenol 2003;181(3):809-817

50 Semelka RC, Brown ED, Ascher SM, et al. Hepatic hemangiomas: a multi-institutional study of appearance on T2-weighted and serial gadolinium-enhanced gradient-echo MR images. Radiology 1994;192(2):401-406

51 Semelka RC, Hussain SM, Marcos HB, Woosley JT. Perilesional enhancement of hepatic metastases: correlation between MR imaging and histopathologic findings-initial observations. Radiology 2000;215(1):89-94

52 Hussain SM, De Becker J, Hop WC, Dwarkasing S, Wielopolski PA. Can a single-shot black-blood T2-weighted spin-echo echo-planar imaging sequence with sensitivity encoding replace the respiratory-triggered turbo spin-echo sequence for the liver? An optimization and feasibility study. J Magn Reson Imaging 2005;21(3):219-229

53 Koh DM, Brown G, Riddell AM, et al. Detection of colorectal hepatic metastases using MnDPDP MR imaging and diffusion-weighted imaging (DWI) alone and in combination. Eur Radiol 2008;18(5):903-910

54 Diffusion-weighted MR imaging of the liver | radiology. Pubs.rsna.org. 2019. Available at: https://pubs.rsna.org/doi/ abs/10.1148/radiol.09090021. Accessed July 21, 2019

55 Park YS, Lee CH, Kim JW, Shin S, Park CM. Differentiation of hepatocellular carcinoma from its various mimickers in liver magnetic resonance imaging: what are the tips when using hepatocyte-specific agents? World J Gastroenterol 2016;22(1):284-299

56 Han JK, Choi BI, Kim AY, et al. Cholangiocarcinoma: pictorial essay of CT and cholangiographic findings. Radiographics 2002;22(1):173-187

57 Chua SC, Groves AM, Kayani I, et al. The impact of 18F-FDG PET/CT in patients with liver metastases. Eur J Nucl Med Mol Imaging 2007;34(12):1906-1914

58 Wiering B, Krabbe PF, Jager GJ, Oyen WJ, Ruers TJ. The impact of fluor-18-deoxyglucose-positron emission tomography in the management of colorectal liver metastases. Cancer 2005;104(12):2658-2670
59 Kinkel K, Lu Y, Both M, Warren RS, Thoeni RF. Detection of hepatic metastases from cancers of the gastrointestinal tract by using noninvasive imaging methods (US, CT, MR imaging, PET): a meta-analysis. Radiology 2002;224(3):748-756

60 Grassetto G, Fornasiero A, Bonciarelli G, et al. Additional value of FDG-PET/CT in management of "solitary" liver metastases: preliminary results of a prospective multicenter study. Mol Imaging Biol 2010;12(2):139-144

61 Kong G, Jackson C, Koh DM, et al. The use of 18F-FDG PET/CT in colorectal liver metastases-comparison with CT and liver MRI. Eur J Nucl Med Mol Imaging 2008;35(7):1323-1329

62 Fong Y, Saldinger PF, Akhurst T, et al. Utility of 18F-FDG positron emission tomography scanning on selection of patients for resection of hepatic colorectal metastases. Am J Surg 1999;178(4):282-287

63 Rohren EM, Paulson EK, Hagge R, et al. The role of F-18 FDG positron emission tomography in preoperative assessment of the liver in patients being considered for curative resection of hepatic metastases from colorectal cancer. Clin Nucl Med 2002;27(8):550-555

64 Ruers TJ, Langenhoff BS, Neeleman N, et al. Value of positron emission tomography with [F-18] fluorodeoxyglucose in patients with colorectal liver metastases: a prospective study. J Clin Oncol 2002;20(2):388-395

65 Sahani DV, Kalva SP, Fischman AJ, et al. Detection of liver metastases from adenocarcinoma of the colon and pancreas: comparison of mangafodipir trisodium-enhanced liver MRI and whole-body FDG PET. AJR Am J Roentgenol 2005;185(1):239-246

66 Sacks A, Peller PJ, Surasi DS, Chatburn L, Mercier G, Subramaniam RM. Value of PET/CT in the management of liver metastases, part 1. AJR Am J Roentgenol 2011;197(2):W256-W259

67 Goldberg SN, Gazelle GS, Compton CC, Mueller PR, Tanabe KK. Treatment of intrahepatic malignancy with radiofrequency ablation: radiologic-pathologic correlation. Cancer 2000;88(11):2452-2463

68 Limanond P, Zimmerman P, Raman SS, Kadell BM, Lu DS. Interpretation of CT and MRI after radiofrequency ablation of hepatic malignancies. AJR Am J Roentgenol 2003;181(6):1635-1640

69 Dromain C, de Baere T, Elias D, et al. Hepatic tumors treated with percutaneous radio-frequency ablation: $\mathrm{CT}$ and MR imaging follow-up. Radiology 2002;223(1):255-262

70 Lubezky N, Metser U, Geva R, et al. The role and limitations of 18-fluoro-2-deoxy-D-glucose positron emission tomography (FDG-PET) scan and computerized tomography (CT) in restaging patients with hepatic colorectal metastases following neoadjuvant chemotherapy: comparison with operative and pathological findings. J Gastrointest Surg 2007;11(4):472-478

71 Eisenberg BL, Harris J, Blanke CD, et al. Phase II trial of neoadjuvant/adjuvant imatinib mesylate (IM) for advanced primary and metastatic/recurrent operable gastrointestinal stromal tumor (GIST): early results of RTOG 0132/ACRIN 6665. J Surg Oncol 2009;99(1):42-47

72 Choi H, Charnsangavej C, de Castro Faria S, et al. CT evaluation of the response of gastrointestinal stromal tumors after imatinib mesylate treatment: a quantitative analysis correlated with FDG PET findings. AJR Am J Roentgenol 2004;183(6):1619-1628

73 Abdulkader I, Cameselle-Teijeiro J, Forteza J. Pathological changes related to imatinib treatment in a patient with a metastatic gastrointestinal stromal tumour. Histopathology 2005;46(4):470-472

74 Shankar S, vanSonnenberg E, Desai J, Dipiro PJ, Van Den Abbeele A, Demetri GD. Gastrointestinal stromal tumor: new nodulewithin-a-mass pattern of recurrence after partial response to imatinib mesylate. Radiology 2005;235(3):892-898 